University of Louisville

ThinkIR: The University of Louisville's Institutional Repository

$5-2008$

\title{
Rural-urban residency, treatment motivation, and health status as factors related to dropout from correctional substance abuse treatment : a policy perspective.
}

Christopher G. Block

University of Louisville

Follow this and additional works at: https://ir.library.louisville.edu/etd

\section{Recommended Citation}

Block, Christopher G., "Rural-urban residency, treatment motivation, and health status as factors related to dropout from correctional substance abuse treatment : a policy perspective." (2008). Electronic Theses and Dissertations. Paper 118.

https://doi.org/10.18297/etd/118

This Doctoral Dissertation is brought to you for free and open access by ThinkIR: The University of Louisville's Institutional Repository. It has been accepted for inclusion in Electronic Theses and Dissertations by an authorized administrator of ThinkIR: The University of Louisville's Institutional Repository. This title appears here courtesy of the author, who has retained all other copyrights. For more information, please contact thinkir@louisville.edu. 


\title{
RURAL-URBAN RESIDENCY, TREATMENT MOTIVATION, AND HEALTH STATUS AS FACTORS RELATED TO DROPOUT FROM CORRECTIONAL SUBSTANCE ABUSE TREATMENT: A POLICY PERSPECTIVE
}

By

Christopher G. Block

M.A., Spalding University, 1992

\author{
A Dissertation \\ Submitted to the Faculty of the \\ Graduate School of the University of Louisville \\ in Partial Fulfillment of the Requirements \\ for the Degree of
}

Doctor of Philosophy

Department of Educational and Counseling

Psychology

University of Louisville

Louisville, Kentucky

May 2008 
Copyright 2008 by Christopher G. Block

All rights reserved 


\section{RURAL-URBAN RESIDENCY, TREATMENT MOTIVATION, AND HEALTH STATUS AS FACTORS RELATED TO DROPOUT FROM CORRECTIONAL SUBSTANCE ABUSE TREATMENT: A POLICY PERSPECTIVE}

\section{By}

Christopher G. Block

M.A., Spalding University, 1992

A Dissertation Approved on

April 10, 2008

By the following Dissertation Committee:

Dissertation Director 


\section{DEDICATION}

I dedicate this work to precious wife, Starr. This achievement would mean nothing to me without her love. She encouraged me to persevere when I had very little desire to finish. For whatever reason, God has brought us together and blessed me beyond measure. My cup doth overflow with abundance. 


\section{ACKNOWLEDGEMENTS}

For her sustained encouragement, patience, and direction I wish to thank the chairperson of my dissertation committee, Dr. Kathleen Kirby. There were undoubtedly times when she, Dr. Purvis, Dr. Leukefeld, Dr. Wagner, or Dr. Stringfield could have removed themselves from my committee because it took so long for me to get to this point. But none of them wavered in their support. I consider each of them not only my mentors, but my friends as well.

My deepest thanks and respect go to Dr. Richard Purvis, whose timing for asking the right questions is impeccable. Your encouragement for greater selfexploration and willingness to make that journey with me has taught me more about what it means to be a psychologist than anyone.

My gratitude also goes to Dr. Matt Hiller at Temple University. Thank you, Matt, for leading me through the rapids of experimental design, statistical analysis, and technical writing. More importantly, thank you for welcoming me into your home and introducing me to your charming family.

Finally, I wish to thank Michele, Allison, and Jamieson at the University of Kentucky Center on Drug \& Alcohol Research for your encouragement and help with the database. 


\begin{abstract}
RURAL-URBAN RESIDENCY, TREATMENT

MOTIVATION, AND HEALTH STATUS AS

FACTORS RELATED TO DROPOUT FROM

CORRECTIONAL SUBSTANCE ABUSE

TREATMENT: A POLICY PERSPECTIVE
\end{abstract}

\author{
Christopher G. Block
}

May 10,2008

Drugs and crime are inextricably connected. Much of the growth in the prisoner population in America is attributable to the misuse and abuse of drugs and alcohol. Offenders who abuse or are dependent on drugs are at high risk for substantial health problems. Without substance abuse treatment, many offenders are destined to continue recycling through an overburdened criminal justice system, costing taxpayers billions of dollars each year in drug-related healthcare costs and lost productivity.

A large body of empirical research demonstrates that treatment helps reduce criminal recidivism and relapse, and is cost-effective. Research also shows that one form of treatment is not appropriate for all types of drug problems or offenders. Appropriate treatment matching that takes into account the severity of an offender's drug problem and their motivation for treatment is necessary to maximize treatment effectiveness, reduce premature dropout, and make the most efficient use of limited fiscal resources. Most of the research cited in the criminal 
justice literature is based on urban samples; comparatively little is known about rural drug offenders and the relationship of treatment motivation and health status to dropout.

This study explored differences in motivation for treatment and mental and physical health status on a group of incarcerated male drug offenders in a residential treatment program in a rural state. Specific attention was given to comparing rural and urban inmates on these factors, and determining whether they were significantly related to dropout from treatment. Results indicate that offenders from rural communities had less desire for help than their urban counterparts, had more physical health problems in the year prior to incarceration, and were nearly four times more likely to drop out of treatment early than inmates from urban areas. Results suggest that residency may be a useful factor to consider in the screening of inmates for substance abuse treatment, and are discussed from a policy perspective vis-à-vis the efficient utilization of limited resources. 


\section{TABLE OF CONTENTS}

PAGE

ACKNOWLEDGEMENTS ................................. iv

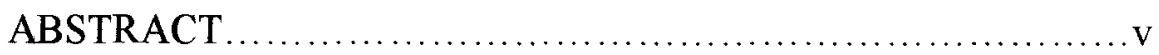

LIST OF TABLES ............................................ vii

\section{CHAPTER}

I. INTRODUCTION $\ldots \ldots \ldots \ldots \ldots \ldots \ldots \ldots \ldots \ldots \ldots \ldots \ldots$

II. LITERATURE REVIEW ............................ 12

The Drugs and Crime Relationship................. 12

Economic Impact of Substance Abuse .............. 15

Fiscal Benefits of Treatment....................... 16

Alternatives to Incarceration....................... 18

Theoretical Models of Addiction....................21

Evolution of Corrections-based Treatment........... 30

The Therapeutic Community -

Community as Method............................ 33

Coerced Treatment, Motivation, and

Treatment Outcome.................................37

Health Issues of Drug Offenders.....................43

Health Service Utilization of Drug Offenders........47

Treatment Matching: Clinical Necessity and

Sound Economic Policy.............................49

Description of Substance Abuse Treatment in the

Kentucky Department of Corrections................ 54

The Issue of Rural Versus Urban Residency......... 55

Research Questions \& Hypotheses.................. 58

III. METHOD ........................................... 60

Program Description...............................6 60

History .....................................60 60

Location ..................................61

Therapeutic Personnel, Programming, and

Treatment Issues..............................62 62

Participants...............................63 
Subject Selection ........................ 65

Experimental Design.........................68 68

Data Analysis............................ 75

IV. RESULTS ............................................ 77

Rural-Urban Comparisons........................ 77

Multivariate Model .............................. 80

V. DISCUSSION .................................... 82

Residency and Physical Health Status.............. 83

Motivation, Attitude Change and Help Seeking..... 83

Characteristics of Rural Offenders................... 85

Limitations ......................................... 87

Implications and Recommendations................90

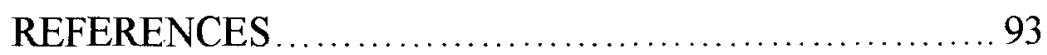

CURRICULUM VITAE ................................. 122 


\section{LIST OF TABLES}

TABLE

PAGE

Table 1: Sample Description...........................................65

Table 2: TCU Motivation................................................. 69

Table 3: Mental health composites from the Addiction Severity Index......

Table 4: HSRI physical health problems ........................... 73

Table 5: Correlation matrix used for the multivariate model...............76

Table 6: Comparison of rural and urban offenders in prison-based substance abuse treatment. 78

Table 7: Stepwise logistic regression model predicting treatment dropout. 


\section{CHAPTER ONE \\ INTRODUCTION}

\section{Statement of the Problem}

The Bureau of Justice Statistics (Bureau of Justice Statistics, 2007) reports that the incarcerated population has grown at a faster rate than in the previous five years. By the end of 2006, the prisoner population in jails and state and federal correctional facilities had exceeded 2.3 million male and female inmates. The rate of incarceration in prison and jail has risen steadily from 458 per 100,000 United States residents in 1990 to 751 per 100,000 at the end of 2006 . State prisons were operating at an estimated $16 \%$ above capacity, while Federal prisons were operating at $39 \%$ above capacity, as admissions have outpaced releases. To accommodate this growth, many states have been forced to build new facilities or have turned to local jails and private prisons to house some of their offenders. The number of prisoners in jails and privately operated facilities grew by $6.6 \%$ and $5.4 \%$ respectively, between 2005 and 2006 . In Kentucky, nearly $30 \%$ of its state inmate population (i.e., sentenced to one year or more) were housed in local jails at the end of 2006 (Bureau of Justice Statistics, 2007). The state's jail population is five times the national average and higher than any other state except Louisiana.

Much of the growth in the prisoner population has been attributed to a rise in the number of inmates incarcerated for drug offenses. The Bureau of Justice Statistics (October, 2006) reports that drug offenders accounted for $21 \%$ of the State prison 
population and $55 \%$ of the Federal prison population in 2004 . The most recent data available from the Federal Justice Statistics Program indicates that the number of drug offenders sentenced to Federal prison rose by $26 \%$ between 2000 and 2006 (Bureau of Justice Statistics, 2007).

Locally, the number of persons in Kentucky convicted of drug-related offenses and sentenced to prison has tripled over the past decade. The Center on Drug and Alcohol Research at the University of Kentucky (1996) found that $59 \%$ of Kentucky inmates met diagnostic criteria for drug dependence $(\mathrm{N}=600)$, and that illicit drug use one month prior to incarceration was twenty times higher among inmates than the general (nonincarcerated) population.

Drug-involved offenders are more likely to have more health problems and chronic health problems (Vlahov, Brewer, Castro, Narkunas, Salive, Ullrich, \& Munoz, 1991; Falkin, Prendergast, \& Anglin, 1994; Marquart, Merianos, Hebert, \& Carroll, 1997) that are either a direct result of their substance use or the result of unhealthy behaviors that are associated with it (e.g., needle sharing, unprotected sex). High rates of HIV and other sexually transmitted diseases, hepatitis C, tuberculosis (Leukefeld \& Haverkos, 1992; Vlahov, 1991; Falkin et al., 1994) and smoking-related illnesses (e.g., asthma, coronary disease, cancer) are a few examples of the many health problems that occur among incarcerated drug offenders. In the 1997 Survey of Inmates in State and Federal Correctional Facilities, nearly one third of State inmates and a quarter of Federal inmates reported having some physical problem or mental condition (Bureau of Justice Statistics, 2001). A sizeable number of inmates housed in jails also report having medical problems. The 2002 Survey of Inmates in Local Jails indicates that more than one third of all jail 
inmates and nearly two-thirds of inmates age 45 or older reported having a current medical problem other than a cold or virus (Bureau of Justice Statistics, November, 2006).

Prior to 1976 correctional health care in America's jails and prisons varied considerably and was inadequate in many facilities. As a result of the landmark case of Estelle v. Gamble (429 US97 [1976]), however, health care services for incarcerated offenders began to improve. In that case, the United States Supreme Court ruled that health care was a constitutional right of prisoners and concluded that "deliberate indifference to the serious medical needs of prisoners constitutes the 'unnecessary and wanton infliction of pain," in violation of the Eight Amendment. Since that time, such organizations as the American Medical Association, National Commission on Correctional Health Care, and American Correctional Association have been involved in the development of standards for correctional health services and their oversight (Thorburn, 1995).

Concurrent with the improvement and growth of correctional health care in the 1970s, public policy regarding the custodial management of mentally ill persons changed. The deinstitutionalization of many mentally ill patients led to the closure of many large state mental hospitals. While the intent of deinstitutionalization was to return the mentally ill to their communities where they could receive needed services and care, in some communities those services never became available. Without proper care and little to no legitimate means of financial support, many of those "walking wounded" ended up being charged and convicted of crimes, and were once again locked up - this time in jail or prison - as an unfortunate consequence of their mental illness. 
Harsher attitudes toward drug-related crime during the 1980s were reflected in public policy changes that had a significant impact on correctional health care. New drug laws were passed that limited judicial discretion in sentencing and mandated longer prison sentences for drug-related convictions. Community-based intermediate sanctions were used less frequently as incarceration became increasingly viewed as the sole sanction for criminal offenses.

These changes led to a surge in prison and jail populations. Not only were correctional facilities forced to accept new inmates, they were also expected to incarcerate many of them for longer periods of time. Public funding cuts, an aging offender population, and increases in the number of incarcerated females placed additional demands on an already weakened health services delivery system. As a consequence, correctional health care services became strained and the gains that had only recently been made were in jeopardy of being lost.

The major impetus for providing drug abuse treatment in corrections has come from the desire to reduce the burgeoning costs of criminal justice services and the cost of health care associated with rapidly increasing numbers of incarcerated chronic drug users with related acute health conditions (Inciardi \& Martin, 1993). Despite an obvious need for help, Peters (1993) notes that relatively few substance-involved offenders have been exposed to treatment prior to entering the criminal justice system. Of the $75-80 \%$ of state inmates determined to be in need of treatment, only $10-15 \%$ prison inmates receive services (Belenko \& Pugh, 2005; Mumola, 1998; Camp \& Camp, 1997). Although more than one-third of treatment admissions are from the criminal justice system, Belenko \& Pugh (1998) reported that a relatively small proportion of state corrections budgets are used to fund substance abuse treatment. Mumola (1998) estimates that only $5 \%$ of state 
corrections budgets are allocated to substance abuse treatment services. As previously noted, many offenders have health conditions that are associated with their substance abuse and require treatment. Depending on the nature and severity of the problem, the cost of incarceration can increase considerably. To illustrate, for FY 2005-2006 the average annual cost to incarcerate one inmate in the primary medical support correctional facility in Kentucky was $27 \%$ higher than the average annual cost to incarcerate one inmate at any of the state's other medium-security institutions $(\$ 25,233.00$ versus $\$ 18,490.00$ ). The cost was also $3 \%$ higher than the state's maximum-security prison $(\$ 24,392.00)$.

In a survey of substance abuse treatment availability in U.S. correctional facilities, the Federal Substance Abuse and Mental Health Services Administration (SAMSHA, May, 2000) and the Department of Justice reported that $40 \%$ of the nation's Federal and State prisons, jails, and juvenile facilities offered some form of service directed at reducing substance use. The report, which was based on the 1997 Uniform Data Set Survey of Correctional Facilities, surveyed 129 Federal prisons, 1,187 State prisons, 3,121 jails, and 3,127 juvenile correctional facilities. Of the 1.6 million adults and juveniles surveyed, only 173,000 were involved in substance abuse treatment. Treatment was broadly defined as services that focused on initiating and maintaining an individual's recovery from alcohol or drug abuse and averting relapse. Treatment modalities included detoxification, group or individual counseling, and methadone or other pharmaceutical treatment for substance abuse.

Since that time, the number of inmates participating in substance abuse programs has increased. The Bureau of Justice Statistics (2004) reports that most of the increase has been seen in self-help groups, peer counseling, and drug abuse education programs. 
The percentage of drug users who received treatment from a trained professional remained relatively unchanged.

One effort to engage more substance-involved offenders in treatment was the Violent Crime and Law Enforcement Act of 1994, which required the Bureau of Prisons to provide appropriate substance abuse treatment to 100 percent of eligible inmates by the end of 1997 and each year thereafter. It exempted many first-time, nonviolent drug offenders from applicable statutory minimum penalties if they completed a drug treatment program while incarcerated (BJS, August 2001). The Act not only served as an inducement for offenders to enter treatment, but represented a significant effort to relieve prison overcrowding by less dangerous criminals.

Given that more than 600,000 prisoners are now being released back into the community each year, the criminal justice system has recently placed considerable emphasis on addressing the reentry needs of newly released offenders. These needs may be considerable for the individual parolee and may include, but are not limited to, family relationships, housing, employment, education, substance abuse and mental health treatment, and life skills training. Unfortunately, there is strong evidence to suggest that many inmates leave prison unprepared to meet the challenges of life in the community (Petersilia, 2001; Austin, 2001). Within the past decade federal funds have been appropriated to operate drug and reentry courts and other reentry programs for the express purpose of helping prisoners reintegrate into society. The Serious and Violent Offender Reentry Initiative (2002) has been a major effort by the Office of Justice Programs to engage state and local agencies in the provision of reentry programming for adult and juvenile offenders. 


\section{Effectiveness of treatment with offenders}

Clearly, there is a substantial need for increased substance abuse treatment in correctional settings. A large body of empirical research supports the idea that providing treatment to substance abusing offenders, especially when it incorporates evidence-based practice, is effective in reducing criminal activity, curbing relapse, and improving health and social functioning if principles of effective treatment are followed (see National Institute on Drug Abuse, 1999; Gerstein \& Harwood, 1990; McClellan et al., 1996; Prendergast et al., 2000). Without it a disproportionate share of drug-abusing offenders is likely to return to substance abuse and criminal behavior (Lipton, Falkin \& Wexler, 1992). Wexler, Lipton and Johnson (1988) report that as many as 60 to $70 \%$ of untreated parolees with histories of cocaine and/or heroin use return to drug use within 3 months after release from incarceration and eventually return to criminal activity. The Drug Abuse Treatment Outcome Study (DATOS) was a federally funded longitudinal study of drug abuse treatment programs and their patients across the United States from 1991 to 1993. Results from DATOS (Hubbard et al. 1997; Simpson et al. 2002) indicate that all major treatment levels (including long-term residential, short-term inpatient, outpatient, and methadone programs) are effective in reducing substance abuse and criminal activity. Early studies by Wexler et al. $(1990)$ and Field $(1989 ; 1992)$ found that corrections-based treatment significantly reduces the likelihood of criminal recidivism. Reductions in drug use and relapse rates after treatment have also been reported by Leukefeld \& Tims (1988), Tims \& Ludford (1984), Knight et al. (1999), and Martin, Butzin, Saum, \& Inciardi, 1999). Numerous other studies have provided evidence for the effectiveness of drug treatment with offenders (e.g., Belenko, Fultz, Lang, \& Sung, 2004a; Mauser et al., 1994). 
Most of the reviewed outcome studies are based on urban samples; few have sampled drug-involved offenders from rural communities and examined how residency and health status may be associated with treatment retention or completion. There is evidence which indicates that rural and urban drug offenders differ in the types of drugs they use, their perceptions of drug problems, their rates of lifetime drug use, and utilization of health services (e.g., Warner \& Leukefeld, 2001; Garrity, Hiller, Staton, Webster, \& Leukefeld, 2002). These differences may impact their motivation to participate in and/or complete substance abuse treatment while they are incarcerated.

While the demand for drug and alcohol treatment services is great, the resources available to meet it are not. Competition for a finite number of dollars available to fund programs is fierce. A crisis has developed in the health care system that is shared by the drug abuse and criminal justice systems - how to provide quality services in a managed care era. Like the rest of the health care field, drug and alcohol service providers have been forced to reassess their services delivery in order to compete successfully for limited resources. From legislators to policy-makers, from grantors to program administrators, difficult decisions regarding the most appropriate allocation of fiscal resources are being made. Equally as difficult are decisions about who gets selected to occupy treatment slots once funding is secured. Consequently, service providers are becoming increasingly pressured to prioritize their admissions and select those patients who are most appropriate for the treatment available and who are likely to benefit from treatment services. This has created an ethical dilemma in the sense that some will be denied the treatment they seek or at best be placed on a waiting list and remain stuck in their abusive cycle while waiting for a treatment slot to open. This is a significant concern particularly with incarcerated 
drug offenders who are more likely to commit crimes after their release if they are not provided with treatment while still in custody.

If criminal justice and general societal health costs are to be contained or reduced in the population of chronic drug users, the criminal justice system must incorporate health risk factors and needs assessments as a routine part of the intake process. As Kendig and his colleagues (1994) have noted, the criminal justice system is increasingly serving as the health care nexus for the diagnosis, assessment, and treatment of chronic drug users. Because prisons deal with those chronic drug users most at risk for health consequences and with the highest service needs, they are an ideal place to organize and provide assessment and drug treatment services. As such, they provide an excellent opportunity to reduce the direct and indirect health service needs and costs in this population.

\section{Purpose of the study}

With these issues in mind, the proposed study will examine the relationship between a set of health-related variables and level of motivation and treatment completion among a group of incarcerated rural and urban drug offenders in a predominantly rural state. Of interest is whether an offender's health status at intake (or time of application) is a useful variable to consider in screening candidates for residential substance abuse treatment placement. Findings may be used clinically to identify candidates who are more likely to drop out of treatment, and politically to support difficult decisions regarding the most efficient utilization of limited treatment resources. The following research questions will be examined:

- Does motivation for treatment differ between rural and urban offenders?

- Is an offender's residency related to premature dropout from treatment? 
- Do rural and urban drug offenders differ in the number and type of health problems they report? Are differences related to treatment dropout?

\section{Significance of the study}

Answers to these questions may add to the literature in some useful ways. First, results will be examined from a policy perspective, vis-à-vis more efficient utilization of limited fiscal resources at a time when the need for services is extremely high. Information obtained from these comparisons may be used to assist policymakers, program administrators, and clinicians in making decisions about where to direct treatment resources in the most fiscally responsible manner. An understanding of the association of self-reported health problems and motivation and treatment completion may offer suggestions for the development of a cost-effective screening tool that may be used at prison intake in a rural state for the purpose of making more appropriate admission decisions, thereby improving the utilization of limited treatment resources.

Such an instrument could be strategically useful in limiting or preventing the occupation of expensive treatment beds by inmates who need other services or who do not desire treatment, and practically useful for treatment and reentry planning. Second, study findings might also yield useful information that may be used to develop less costly programming for inmates who do not require the structure and intensity of a six-month modified TC program. Third, an examination of differences along a rural—urban dimension may offer direction toward the development of programs or services aimed at addressing the unique needs or issues faced by prisoners, particularly those from rural communities. Hence, the results of this study will be used to examine a number of questions regarding the treatment of chronic drug abusers within the Kentucky Department of Corrections. 


\section{CHAPTER TWO \\ LITERATURE REVIEW}

\section{The Drugs and Crime Relationship}

The relationship between drugs and crime has been firmly established (e.g., Belenko, 2001; Chaikin \& Chaikin, 1982; Chaiken \& Chaiken, 1990; Inciardi, Martin, Butzin, Hooper, \& Harrison, 1997; Elliot \& Huizinga, 1984) and is axiomatic among experts in the field of correctional substance abuse treatment. Estimates indicate that $80 \%$ of incarcerated individuals reported past drug use or have some degree of drug or alcohol involvement (Mumola, 1999; Belenko \& Pugh, 1998). As Leukefeld \& Tims (1988) have observed, "drug use does not necessarily initiate criminality or criminal careers, but it does serve to intensify and perpetuate them." Illicit drugs can "lock users into patterns of criminality" well into adulthood. Lifestyles that revolve around drug use encourage crime and discourage participation in the legitimate economy (Leukefeld \& Tims, 1988). Drugs may exert powerful effects on the user's behavior, such as generating violence and other illegal activity associated with drug trafficking (Office of National Drug Control Policy [ONDCP]; March, 2000).

Since 1974 the Bureau of Justice Statistics has compiled detailed information on criminal offenders in State correctional facilities, particularly special populations including drug and alcohol offenders. Data from Federal facilities were collected for the first time in 1991 and have been collected every five or six years. Inmate surveys are 
conducted every five or six years. Near the end of the 1990 s $57 \%$ of the nation's prisoners reported using drugs regularly during the month prior their arrest, and more than half $(51 \%)$ reported the use of drugs or alcohol while committing their offense (Center on Addiction and Substance Abuse (CASA), 1998; Mumola, 1999). More recently, according to the 2004 Survey of Inmates in State and Federal Correctional Facilities, more than $50 \%$ of State inmates and $45 \%$ of Federal inmates met diagnostic criteria for drug abuse or dependence. More than two-thirds of State prisoners reported that they had used drugs regularly at some point in their lives. Nearly three-quarters (72\%) of State inmates and 50\% (up from 45\% in 1997) of Federal inmates reported using drugs in the month prior to their offense. The survey also found that: one third of State prisoners and one quarter of Federal prisoners reported that they were under the influence of drugs at the time of their offense; $17 \%$ of State and $18 \%$ of Federal prisoners committed their crime to obtain money for drugs; one third of property offenders in state prisons reported drug money as motive for their crime; 1 in 4 drug offenders reported drug money as a motive. These figures were largely unchanged from 1997 (Bureau of Justice Statistics, October, 2006). The drugs—crime link has also been reported elsewhere. For example, data from the Arrestee Drug Abuse Monitoring (ADAM) system indicate that $64 \%$ of male arrestees in 39 major U.S. cities tested positive for drugs at the time of their arrest (National Institute of Justice, 2003). An equivalent percentage of female arrestees from 25 cites tested positive for drugs at the time of their arrest.

Since 1990 the number of female prisoners in State or Federal correctional facilities has increased $108 \%$, and grew at an average annual rate of $7.6 \%$ (Bureau of Justice Statistics, August, 2001). Female drug offenders accounted for the majority of the 
total growth of female inmates (33\%; Bureau of Justice Statistics, July, 2002). Like their male counterparts, a significant percentage of female offenders report drug use prior to or during the commission of their offenses. In $200459 \%$ of women in State prisons used drugs in the month preceding their offense. The number of female inmates held in Federal prisons who used drugs in the month prior to their offense rose 11 percentage points from 1997 to $48 \%$ (Bureau of Justice Statistics, 2006).

Substance-abusing offenders are responsible for committing a significant proportion of serious crime in the United States. Chaiken and Chaiken (1990) found that the use of heroin or multiple drugs was significantly related to the prevalence of predatory crimes. In an earlier study, Chaiken (1986) reported that heroin users, considered by many to be the most predatory, committed 15 times more robberies, 20 times more burglaries, and 10 times more thefts than non-using offenders. Active drug use among heroin addicts in Baltimore and New York was found to accelerate the users' crime rate by a factor of four to six, and crimes committed by users were at least as violent, if not more so, than people who did not use drugs (Ball, Shaffer, \& Nurco, 1983). As many as $28 \%$ of all inmates in 2004 who reported alcohol or drug use at the time of their offense were incarcerated for a violent crime (e.g., homicide, sexual assault, robbery, assault; Bureau of Justice Statistics, 2006). The emergence of crack cocaine use in the mid-1980s has led to increases in crack-related crime and in the number of inmates in State prisons with crack histories (Fagan, Belenko, Johnson, Chin, \& Dunlap, 1990). Studies of crack-related crime indicate the rate is as high as or higher than heroin-related crime and is more violent (Lipton, 1995). 
Alcohol has also been associated with the commission of violent crime. In 1996, $36 \%$ of the estimated 5.3 million convicted offenders under correctional supervision had been drinking alcohol when they committed their offense. According to the National Crime Victimization Survey, in 1999 there were 7.4 million victims of violent crime age 12 or older. Of these, $28 \%$ were certain the offender was using drugs alone or in combination with alcohol while committing the crime. Drinking offenders committed over one third of the rapes or sexual assaults of persons older than 12 , and over one quarter of the aggravated and simple assaults, according to victims' perceptions (Bureau of Justice Statistics, December 2001).

\section{Economic Impact of Substance Abuse}

The high societal costs of drug abuse have been well documented (e.g., Harwood, Hubbard, Collins, \& Rachal, 1988; Rice, Kelman, Miller, \& Dunmeyer, 1990). These costs are particularly dramatic for drug abusing offenders whose criminal activity, criminal justice costs, usually poor health status, and use of expensive public health services place heavy burdens on the individual taxpayer and society. According to the National Institute on Drug Abuse (2006), the estimated societal cost of illegal drug abuse in 2002 was $\$ 180.9$ billion. Productivity losses related to incarceration and drug related illness accounted for the majority of these costs. Rice et al. (1990) have noted that the societal costs of alcohol abuse and its consequences are even greater. Harwood (2000) reports that in 1998 the total economic cost of alcohol abuse was $\$ 185$ billion, of which more than 70 percent were attributed to lost productivity, including losses from alcoholrelated illness, premature death, and crime. 
Economic costs are not limited to health service expenditures or productivity losses. In its 1998 report Behind Bars: Substance Abuse and America's Prison Population, the Center on Addiction and Substance Abuse (CASA) estimated that \$24 billion of $\$ 30$ billion spent in 1998 on corrections was spent incarcerating offenders whose criminal behavior was associated with drugs and/or alcohol. Most recent data submitted by the Federal Bureau of Prisons indicates that in 2001 the average cost to incarcerate one prison inmate in a Federal prison was $\$ 22,632$ (Bureau of Justice Statistics, June 2004). The average for State inmates for the same time period was $\$ 22,650.00$.

\section{Fiscal benefits of treatment}

Estimating substance abuse treatment cost savings can be difficult. Assumptions about the societal costs associated with substance abuse and the methods for calculating crime costs and earnings vary. Evidence generally supports the idea, however, that substance abuse treatment results in cost savings to society and to taxpayers. Cost-benefit analyses of substance abuse treatment programs have shown that for every treatment dollar invested a greater return can be realized in terms of reduced crime, avoided costs of medical care, and improved productivity (Mauser, Van Stelle, \& Moberg, 1994). In 1994 the oft-cited California Drug and Alcohol Treatment Assessment (CALDATA; Gerstein, Johnson, Harwood, Fountain, Suter, \& Malloy, 1994) published its findings on the cost-effectiveness of publicly supported treatment programs in that state. For each dollar spent on drug treatment taxpayers saved $\$ 7$ in future costs. The largest savings came from reductions in crime, followed by reductions in lost wages and health care costs. According to the National Treatment Improvement Evaluation Study from the 
Center for Substance Abuse Treatment (CSAT), between 1993 and 1995 the estimated average ratio of benefits (i.e., savings or cost offsets) to treatment cost was 3 to 1 (ONDCP, March, 2001). Cost-benefit studies of treatment and other drug abuse interventions such as drug courts have been conducted in other states as well (Zarkin, French, Anderson, \& Bradley, 1994; French, 1995; French \& Martin, 1996; Logan, Hoyt, McCollister, French, Leukefeld, \& Minton, 2004). The 2002 Kentucky Substance Abuse Treatment Outcome Study (Walker, Logan, Bradshaw, Leukefeld, Goltz, and Stevenson, 2003) examined intake and follow-up data on 838 substance abuse treatment clients statewide and calculated the avoided costs of substance abuse treatment. Significant reductions in substance use, improved ratings of physical and mental health, decreased criminal activity, and increased employment were found. Walker et al. (2003) estimated that Kentucky taxpayers saved $\$ 4.03$ for every dollar spent on treatment. They note that it is difficult to compare cost saving findings from other nationally recognized outcome studies to Kentucky. Those studies have focused on treatment modalities such as longterm residential treatment (Hubbard, Marsden, Rachal, Harwood, Cavanaugh, \& Ginzburg, 1989), which are not used in Kentucky (Walker et al., 2003). Some of those studies include the Treatment Outcome Perspective Study (TOPS) (French, Zarkin, Hubbard, \& Rachal, 1991), the Drug Abuse Treatment Outcome Study (DATOS) (Hubbard, Craddock, Flynn, Anderson, \& Etheridge, 1997), and CALDATA (Gerstein et al., 1994).

In their extensive review of the economic benefits of drug treatment, Belenko, Patapis, and French (2005) summarized the findings of 126 economic evaluations and unpublished reports between 1990 and 2004. Positive economic benefits were 
consistently found across a variety of settings, populations, methods, and time periods. The primary economic benefits accrued from reduced crime (including incarceration and victimization costs) and post-treatment reductions in health care costs and increased employment. Residential treatment was found to be cost effective but only in conjunction with post-release aftercare services. For example, Griffith, Hiller, Knight, \& Simpson, (1999) examined the cost-effectiveness of intensive in-prison treatment while controlling for risk of recidivism. Three-year outcome data showed that treatment was cost-effective only when aftercare was completed after intensive treatment and that the largest economic impact was associated with high-risk cases. Similar findings have been reported elsewhere (e.g., McCollister, French, Prendergast, Wexler, Sacks, \& Hall (2003a; McCollister, French, Inciardi, Butzin, Martin, \& Hooper, 2003b; McCollister, French, Prendergast, Hall, \& Sacks, 2004). Griffith, et al. (1999) encourage treatment assignment based on the offender's level of need and the provision of aftercare services upon release from incarceration.

\section{Alternatives to incarceration}

By comparison, treating and supervising offenders in the community is a less costly alternative to incarceration (Anglin \& Hser, 1990; Anglin, Longshore, Turner, McBride, Inciardi \& Prendergast, 1996). The drive by judicial, executive, and legislative bodies, correctional administrators, and treatment professionals to develop alternative, less expensive ways to supervise offenders with substance use disorders has been spurred by prison and jail overcrowding, escalating incarceration costs, inmate medical expenses, concerns about threats to public safety by violent offenders, economic benefits of treatment, and determinate sentencing practices. Home incarceration programs and 
electronic surveillance technology, for example, permit non-violent offenders to live and work in the community at a fraction of the cost of incarceration. Recently, the Kentucky Department of Corrections obtained legislative approval to expand its home incarceration program to include state inmates housed in jails (Kentucky Department of Corrections, 2006). The expansion is expected to save the DOC thousands of dollars annually in inmate housing costs. Since 2003 the state of Alabama has operated two parole boards, which has shaved 5,000 from what the prison population would have been without the second board. The state is also establishing "technical violator centers" so that parolees arrested on technical violations do not end up back in prison. (Press-Register, May 23, 2007). Several states are now using Global Positioning Systems (GPS) to track the movements of offenders (e.g., sex offenders) in the community. Other states are considering the use of GPS as well.

The Treatment Accountability for Safer Communities (originally named Treatment Alternatives to Street Crime, or TASC) program was created in the 1970s and was one of the original case management models to increase access to substance abuse treatment services for criminal justice clients. Still in operation, the primary function of TASC programs is to link drug addicted offenders with appropriate treatment services in the community and to monitor their progress while in treatment. At some sites, TASC provides services to offenders throughout the entire criminal justice process, from screening at arrest to community reentry, thus bridging the gap between the treatment and criminal justice systems (Cook, 2002). Some programs also address the needs of the mentally ill and dually diagnosed. TASC programs have been found to retain clients in treatment longer than non-TASC clients (Inciardi \& McBride, 1991), and have been 
found to generate better crime reduction among more serious offenders, as compared to lower risk offenders (Anglin, Longshore, \& Turner, 1999). Today there are more than 200 members of the national TASC association.

The proliferation of drug courts since the first began in Dade County, Miami, Florida in 1989 has diverted thousands of non-violent offenders with drug problems out of jails and prisons and into treatment and community resources. At the end of 2006 there were 1,927 drug courts operating in all fifty states and U.S. territories. Drug courts combine intensive judicial supervision, mandatory drug testing, escalating sanctions, and treatment to help substance-abusing offenders break the cycle of addiction and reduce the crime associated with it. Drug courts are unique in relation to traditional courts in several philosophical and structural ways. Unlike traditional criminal courts, which rely on penal and criminal procedure laws to reach a fair and legal resolution of a criminal case, drug courts typically set aside a determination of guilt and focus on the offender's substance abuse needs and related problems to reduce relapse and criminal recidivism (Belenko, 2002). Drug court judges exercise their judicial authority to leverage defendants into treatment and work with treatment systems to promote abstinence, accountability, and prosocial behavior. Regular status hearings to monitor an offender's progress in treatment and compliance with supervision are seen as necessary components of the drug court operation (Belenko, 1998). By comparison, for nonviolent offenders who would be candidates for drug court, the typical adjudication process would result in probation or a short jail sentence, with little treatment or close community supervision (Taxman, 1998). A drug court judge's courtroom style and personality are often seen as key factors in the success of the drug court (Marlowe \& Kirby, 1999). 
The application of operant conditioning principles promotes behavioral changes not only by punishment but also by rewarding successes and goal achievement. Defendants who are noncompliant with drug court requirements and/or violate the conditions of treatment are subject to a continuum of graduated sanctions, up to and including incarceration. Conversely, rewards for compliance and successes are given to offenders who do well in treatment. Upon completion of treatment the defendant's charges may be dismissed or their probation sentences reduced. Several studies have found that drug court participation reduces criminal activity while under drug court supervision and for one year following drug court participation (Belenko, 2002). However, little is known about the long-term impact of drug court participation on recidivism.

\section{Theoretical models of addiction and approaches to treatment}

The history of drug and alcohol treatment shows that numerous models have been applied, each reflecting a different view of the nature and etiology of substance abuse (Hester \& Miller, 1995). Biochemical abnormalities (Milam \& Ketcham, 1981), social learning processes (Peele, 1985), family pathology (Steiner, 1971), personal choice (Fingarette, 1988), and sociocultural influences (Cahalan, 1987) are among the many and varied theories that have been offered to explain addiction. Likewise, each model has its own ideas regarding how addiction should be treated and the effectiveness of specific treatment interventions, but all recognize the chronic and relapsing nature of addictive disorders. The following is a brief historical overview of various models of substance use problems. 


\section{Moral Model}

Moral models are generally associated with alcoholism and attribute substance use disorders to willful violations of societal rules and norms. Personal choice is seen as the primary causal factor in substance use problems. Under this model individuals are seen as making decisions and exercising choices to use substances in a problematic fashion, and are capable of making more responsible choices.

\section{Temperance Model}

The temperance view predominated in the United States from the late $19^{\text {th }}$ century until the repeal of Prohibition in 1933. As the name suggests, the temperance movement emphasized the cautious and moderate use of alcohol. The model correctly views alcohol (drugs) as a hazardous substance with great potential for inflicting personal harm. As the movement progressed, temperance advocates increasingly began to believe that alcohol could not be used safely or in moderation. The only recourse for persons who drank was abstinence or face eventual death with continued consumption.

The temperance model assumes the cause of alcohol problems is alcohol itself. Problems are attributable to the inherent addictive and destructive properties of the substance. From the temperance perspective, either temperance or abstinence are appropriate interventions to reduce or prevent alcohol problems. Another approach would be to control the cost, availability, and promotion of alcohol to the public.

\section{Spiritual Model}

Alcoholics Anonymous (AA) emerged shortly after the repeal of Prohibition and alcohol again became freely available, and is the approach most identified with spiritual models of alcohol problems. Under this model persons with alcohol problems are seen as 
suffering from a condition they are incapable of overcoming on their own. In order to recover, they must turn their life over to a "higher power" and follow the 12 steps that provide guidelines for sober living. Abstinence is considered to be the only route to recovery. Though technically atheoretical, AA acknowledges that biological, social, and psychological factors are involved in the development of alcohol problems. However, an unmistakable emphasis on a spiritual approach to recovery makes this model distinct from any other.

\section{Disease Model}

The disease model, oftentimes confused with the AA approach, ascribes alcohol problems to constitutional differences between alcoholics and nonalcoholics. Compared to nonalcoholics, persons with alcohol problems are seen as incapable of drinking in moderation and suffering from a condition that is characterized by a progressive loss of control over the ingestion of alcohol. The condition is considered to be chronic, irreversible and incurable; however, its progressive course can be stopped through complete abstinence. Treatment involves helping clients to accept their diagnosis and persuade them to abstain from the use of alcohol for the rest of their lives.

Because persons with alcohol problems are seen as possessing a disease, much of the negative social stigma alcoholics face because of their condition may be avoided or lessened. AA adherents have embraced this view, as have many in the medical community who believe medical treatment is the preferred course of action. Detractors of the disease model recognize that biological factors influence choices, but reject the idea that our choices are dictated by them (Horvath, 2000). Some argue that alcoholics and drug abusers use the model to avoid taking responsibility for their addiction(s) since they 
cannot control a medical disease. They contend the model fosters dependence on someone or something else to bring about needed change. The spiritual model has been criticized on similar grounds.

\section{Biological Model}

Biological models emerged in the 1970s and emphasize heredity and brain physiology as causal factors of alcoholism. Thus, they are sometimes blended with disease models. Evidence of a hereditary link comes from findings that children whose parents are alcoholic are at higher risk for developing the disorder themselves. Some drugs, such as methamphetamine, produce toxic effects on the brain, produce dramatic behavioral changes, and alter brain structure. New discoveries made possible by the latest advances in brain imaging technology have confirmed that drug addiction is a chronic brain disease (Leshner, 1997) and are revealing the neuroanatomical correlates of addiction. For example, numerous magnetic resonance imaging (MRI) studies have shown that addictive drugs can cause volume and tissue changes in the frontal cortex, the region of the brain that supports logical thinking, self-control, goal-setting, and planning. Reductions in cortical gray matter have been found in polysubstance abusers (Liu, Matochick, Cadet, \& London, 1998), stimulant abusers (Kim, Lyoo, Hwang, Chung, Sung, Kim, et al., 2005), and alcoholic patients (Pfefferbaum, Sullivan, Mathalon, Shear, Rosenbloom, \& Lim, 1995).

Volume changes have been found in other brain structures as well. Enlarged basal ganglia, a large collection of nuclei important for smooth, coordinated movement, have been found in cocaine-dependent (Jacobsen, Giadd, Gottschalk, Kosten, \& Krystal, 2001) and methamphetamine-dependent (Jernigan, Gamst, Archibald, Fennema-Notestine, 
Mindt, Marcotte, et al., 2005) subjects relative to healthy subjects. Smaller hippocampi have been found in chronic methamphetamine abusers (Thompson, Hayashi, Simon, Geaga, Hong, Siu, et al., 2004). The hippocampus is part of the limbic system (often referred to as the "emotional brain"), and is important for learning and memory, for converting short-term memory to more permanent memory, and for recalling spatial relationships in the world around us. Children of alcoholic parents have been found to have relatively small amygdalas (Hill, DeBellis, Keshavon, Lowers, Shen, Hall, et al., 2001). The amygdala is also a part of the limbic system and is involved in memory, emotion, and fear.

Positron emission tomography (PET) and single photon emission computed tomography (SPECT) have established the role of dopamine in addiction. Dopamine is a neurotransmitter involved in brain processes that control movement, emotional response, and the ability to experience pleasure and pain. During pleasurable activities dopamine is released into the nerve synapse. Under normal conditions, excess dopamine is taken back up by the sending neuron (a process called reuptake) in order to keep the level of the neurotransmitter within normal limits. Some drugs, such as cocaine and methylphenidate, prevent the reuptake of dopamine, leaving more dopamine in the synapse (Drevets, Gantier, Price, Kupfer, Kinehan, Grace, et al., 2001; Volkow, Wang, Fowler, Logan, Gatley, Wong, et al., 1999). As a result, the abuser experiences a sense of euphoria. Lower levels of dopamine receptors found among abusers of alcohol (Volkow, Wang, Fowler, Logan, Hitzemann, Ding, et al., 1996b), cocaine (Volkow, Fowler, Wang, Hitzemann, Logan, Schlyer, et al., 1993) heroin (Wang, Volkow, Fowler, Logan, Hitzemann, Pappas, et al., 1997), and methamphetamine (Volkow, Chang, Wang, Fowler, 
Leonito-Yee, Fransechi, et al., 2001) have led investigators to speculate that these persons are highly susceptible to addiction because they experience less pleasure from ordinary activities and accomplishments and, therefore, seek to derive it from drugs that increase dopamine levels in the brain.

Fortunately, some changes can be reversed with abstinence. In the Kim et al. (2005) study, methamphetamine abusers who had remained abstinent for more than six months showed gray matter closer to normal than others with a shorter period of abstinence. In a study by Bendszus, Heinz, Weijers, Weisbach, Wanmuth-Metz, Bartsch, et al., (2001), alcoholics began showing signs of recovery in frontal cortex volume within weeks of stopping drinking.

For many severely addicted individuals, an abstinence only approach to stopping drug use is unrealistic. The evolution of pharmaceutical treatment for drug dependency has given hope to thousands of addicts. Drugs such as naltrexone and buprenorphine have been shown to be effective in the treatment of alcohol and drug dependency by blocking opioid receptors in the brain. By reducing the cravings that are often experienced after drug cessation, an addict can focus attention on other aspects of treatment recovery.

\section{Characterological Model}

Characterological models are rooted in psychoanalytic theory and subscribers to such a model attribute alcohol problems to disturbances in personality. Several hypotheses have been proposed, including severe unresolved dependency conflicts that result in early fixation of normal psychological development, low self-esteem, latent homosexuality, sex-role conflicts, and a need for power and control. These models assume persons with alcohol problems have particular personality characteristics that 
make them susceptible to substance use disorders. Addicts are also believed to display primitive defense mechanisms (e.g., denial) at a high level. These assumptions led many to also assume the existence of an "alcoholic or addictive personality," a belief that has not been confirmed by research (Miller \& Rollnick, 1991). Psychotherapy to resolve underlying conflicts and promote a more mature level of functioning would be the intervention of choice from the characterological perspective.

\section{Conditioning/Social Learning Model}

Conditioning and social learning models take the position that substance abuse problems are learned habits and, as such, respond to basic learning principles like positive and negative reinforcement. A central assumption of these models is that drinking will increase if it is followed by a rewarding consequence or if it prevents a negative consequence.

A focus of these models is on the interactions between the individual and the environment and their effects on shaping patterns of substance use. Research focusing on the influence of peers and modeling on drinking behavior has found that peers' heavy drinking will evoke increased consumption in others around them.

Social learning perspectives also emphasize the importance of coping skills. The use of alcohol can be viewed as a maladaptive strategy for dealing with interpersonal conflict or problems in the client's environment. Interventions are aimed at altering the client's relationship to his or her environment and developing new skills and coping behaviors. 


\section{Biopsychosocial Model}

According to the biopsychosocial model, addiction is an interaction of biology and brain, psychological, social and environmental factors, and is used to bridge disease and spiritual models of addiction with learning theory. Many criminal justice treatment programs have adopted this model.

Basic components of offender AODA treatment include relapse prevention (Marlatt \& Gordon, 1985) to identify predictable environmental and psychological antecedents to relapse, and learn more effective strategies to deal with them. Offenders are also taught how to correct the cognitive distortions they frequently make to justify and excuse their criminal behavior (Yochelson \& Samenow, 1984). Training in life skills (e.g., effective communication, job training, interview skills, resume writing, budgeting, etc.) is usually provided in the latter stages of treatment prior to the offender's release from incarceration. Treatment programs typically also require participation in 12-step meetings during residential treatment as well as aftercare. More successful programs carry out each of these interventions within a philosophical framework that demands client accountability and responsibility.

\section{Harm Reduction Model}

Harm reduction is a public health philosophy that rests on the assumption that some persons will never discontinue their drug use. The model is more concerned with reducing the harmful consequences of drug use than reducing the use of drugs themselves. The absence of any expectation of a reduction in drug use makes it distinctly different from other drug policies (Single, 1995: Prendergast \& Podus, 2000). Harm reduction has been slow to gain acceptance in the United States, where program 
effectiveness has been determined mainly by reductions in drug use. Programs that could not demonstrate decreased drug use were considered unsuccessful. By contrast, programs following a harm reduction approach would be considered successful if they could demonstrate reductions in harm associated with drug use even if there was no decline in drug use (MacCoun, 1998).

Harm reduction initiatives range from widely accepted ideas, such as designated driver campaigns, to more controversial initiatives, such as the provision of condoms in public schools, needle exchange programs or safer injection sites for intravenous drug users, drug legalization, and heroin maintenance programs. Advocates of harm reduction argue that no one should be denied health care or social security because they take risks or engage in certain behaviors that are illegal or that society considers immoral. Some view the prohibition of drugs as discriminatory and counter-productive, and point to evidence for the medicinal use of some drugs, such as marijuana, to support their argument. Many contend that laws criminalizing drug users and incarceration are ineffective in reducing drug use and the harms associated with it, and favor treatment of drug addiction by qualified professionals over incarceration. From this perspective, establishing drug courts and diverting non-violent drug offenders to community treatment are seen as more compassionate and protective of human dignity.

Critics of the model argue that the approach condones and even facilitates dangerous behaviors. They fear that by making dangerous behavior safer, it may lead to an increase in that behavior by persons who would otherwise be deterred by the potentially dangerous outcomes of the behavior. 


\section{Evolution of Corrections-based Treatment}

The Federal Bureau of Prisons (BOP) helped pave the way for corrections-based treatment programs. Treatment for incarcerated Federal offenders formally began in 1935 with the opening of the U.S. Public Health Service Hospital in Lexington, Kentucky. A second facility was opened in 1938 in Fort Worth, Texas. These hospitals, which were originally named "narcotic farms," evolved into clinical research centers and are now part of the Federal prison system. Despite the early presence of these programs, correctionsbased treatment has not been without its critics and setbacks.

A major summary by Robert Martinson (1974) reviewed the outcomes of 231 treatment programs for criminal offenders conducted between 1945 and 1967. "The Effectiveness of Correctional Treatment" concluded that "rehabilitative efforts....have no appreciable effect on recidivism" (1974: 25). This conclusion was widely interpreted as "nothing works" and was treated as fact in the corrections field (Lipton, 1995).

Critics of the report, however, (e.g., Gendreau, 1981) argued against this conclusion, and instead questioned the validity of the research upon which it was based. They argued that inadequate research methodology and program implementation made it impossible to draw any conclusions. Others (e.g., Palmer, 1975, 1983) argued that many positive instances of success were overlooked and little attention was given to important issues such as the degree of goodness-of-fit between the type of offender and the type of treatment provided (i.e., treatment matching). Since the publication of Martinson's essay, a number of evaluative studies have concluded that correctional treatment can be effective in reducing recidivism (e.g., Cullen \& Gilbert, 1982; Van Voorhis, 1987; Lipton, 1992, 1994). Martinson later revised his original conclusion after further review 
of the research and stated, "some treatment programs do have an appreciable effect on recidivism" (Martinson, 1979: 244).

Based on the results of hundreds of studies documenting the effectiveness of substance abuse treatment, in 1990 the National Association of State Alcohol and Drug Abuse Directors published "Treatment Works," which stated that, "... substance abuse treatment is effective in reducing substance abuse, increasing employment, improving psychological adjustment, and decreasing crime..." Not everyone agrees that treatment works, however. Apsler (1994), for example, has questioned the level of statistical rigor used to determining the effectiveness of treatment. "Treatment works" is now considered too broad a statement. Questions regarding the effectiveness of treatment have been reformulated and are now concerned with such issues as: What kind of treatment works? For whom? Under what conditions? For how long? (Prendergast \& Podus, 2000).

Despite mounting challenges to the "nothing works" article, its impact rippled throughout the United States and gave rise to an anti-rehabilitation sentiment among policymakers and the public that persisted throughout the 1980's and into the 1990's (Field, 2002). During the mid-1980's cocaine use doubled in many cities and tripled in some, while the use of other drugs (e.g., heroin, PCP) declined or remained stable (Wish $\&$ O'Neil, 1989). The advent of crack cocaine during the same time period led to increased violence, gang activity, and shootings. The so-called "war on drugs" resulted in massive numbers of drug-abusing offenders entering the criminal justice system (Inciardi, 1993). The system's initial response was to "lock 'em up" as tougher sentences for drug dealers and users were mandated by state legislators (Wexler, 1994). As a consequence of that policy, the proportion of incarcerated drug users rose to its highest level in history at 
the time (Reuter, 1992). The growth of prison and jail populations prompted courts to issue orders limiting overcrowding, leading to the costly construction of more prisons and jails.

The Office of National Drug Control Policy (ONDCP) was formed out of the Anti-Drug Abuse Act of 1988, and was established to develop strategies to reduce the supply and demand for dangerous drugs through various activities including treatment (Leukefeld, Pickens, \& Schuster, 1992). Each year since 1989 the ONDCP has overseen the implementation of a national drug control strategy that sets in motion policies and programs targeted at achieving these goals. The Bush administration's 2002 National Drug Control Strategy set goals of reducing the use of illegal drugs $10 \%$ in two years and $25 \%$ in five years (ONDCP National Drug Control Strategy, 2002, p. 3). These goals have reportedly been met among the 12-17 age group (ONDCP, February 2006). An estimated \$19.2 billion was requested to fund the President's FY 2003 strategy (ONDCP, National Drug Control Strategy, FY 2003 Budget Summary, 2002, p. 4), of which $\$ 8.07$ billion was requested for Department of Justice programs including domestic law enforcement, interdiction, and treatment efforts. Since that time, budget requests have dropped significantly ( $\$ 12.9$ billion for FY 2008), but treatment has consistently remained one of three key Strategy elements (ONDCP, February, 2007).

Wexler (1994) notes that correctional policy has taken a new direction that is based on the accumulation of research demonstrating the efficacy of corrections-based treatment. Correctional policy has shifted from a primary emphasis on security and control toward an emphasis on treatment and rehabilitation. The National Task Force on Correctional Substance Abuse Strategies, convened in 1989 by the National Institute of 
Corrections, recommended that treatment be made a policy goal on a par with offender control if strides were to be made in reducing long-term substance abuse and associated criminal activity (Department of Justice, National Institute of Corrections, 1991). As a result of this shift in emphasis, the number of prison-based treatment programs has begun to increase as correctional administrators become increasingly aware of the benefits of offering such programs, vis-à-vis recidivism, relapse rates, overcrowding, and general inmate management. Additionally, legislators and policymakers are realizing that states can no longer bear the enormous fiscal burden of building more jails and prisons, and now recognize the economic and social benefits of treating offenders while they are incarcerated.

\section{The Therapeutic Community - "Community as method"}

The contemporary therapeutic community (TC) for the treatment of drug abuse and addiction has been in existence for about forty years and owes many of its essential elements to the Oxford Group, Synanon, and Alcoholics Anonymous. Descriptions of these early programs and their influence on the modern TC can be found in the writings of Glaser (1974) and DeLeon (2000). Briefly, however, those precursors shared some common ideas and practices (e.g., mutual concern, accountability, self-examination, and working with others) that are found in today's correctional TCs.

The use of the community, comprising treatment staff and persons in recovery, as the primary agent of change separate TCs from other treatment approaches. DeLeon (2000) refers to this approach as "community as method." Although change is the primary responsibility of the individual, the individual is also expected to assume partial responsibility for the recovery of their peers. This process of "mutual self-help" is 
another fundamental TC principle and illustrates the importance of working together to manage addiction problems. The primary objective of TCs is to create a peer culture or milieu that promotes increasing acceptance of responsibility and accountability among its members. Through a variety of structured and unstructured ways, TC residents are encouraged to reflect upon and change attitudes, perceptions, and behaviors associated with drug use.

Ideally, TCs are self-contained facilities separated from the drug-related environment. Within a correctional setting, it is often not possible to completely segregate TC participants from the general prison population. Although TC residents may live and receive treatment within a separate housing unit, some activities (e.g., recreation, meals, medical appointments) cannot practically be carried out within program walls. Space limitations, staffing patterns, or other prison constraints have led to the development of modified TCs with shorter durations of stay (3, 6, and 12 months), as well as TC-oriented day treatment models (e.g., Karson \& Gesumaria, 1997).

TC residents are expected to adhere to strict behavioral norms. A system of rewards and sanctions is used to reinforce these norms and to promote the development of self-control, accountability, and personal responsibility. As the resident progresses through the program they are expected to take on increasingly important roles, which carry greater responsibilities and privileges. Through a variety of structured and unstructured activities (e.g., individual and group therapy, peer group sessions, confrontation, role-play, community-based restitution), residents learn how to change negative patterns of thinking and behavior that are associated with drug use. 
Positive outcomes associated with TC participation have been reported in several studies. For example, in the DATOS study, post-treatment levels of cocaine, heroin, and alcohol use, criminal behavior, unemployment, and indicators of depression among persons who completed TC treatment were lower than pre-treatment levels. It is noted that two-thirds of admissions in the DATOS sample had a criminal justice status at the time of admission, and about one-third were referred to treatment by the criminal justice system.

Once released from incarceration, a sizable number of offenders are returned to prison on technical parole violations and positive urine screens. Even with correctionsbased treatment, parolees are most likely to relapse within the first 3 to 6 months after release unless they are provided with appropriate aftercare services (Hitchcock, Stainbeck, \& Roque, 1995). Aftercare focuses on assisting released prisoners in making a successful transition to their community and is considered critical to successful treatment outcomes (Griffith et al., 1999). Services may include outpatient treatment, self-help and support groups, education, job training, and approaches that facilitate the development and maintenance of coping skills, particularly how to deal effectively with high risk situations, lapses, and relapses, and correcting criminal thinking errors (Samenow, 1984). A high degree of coordination is necessary between the correctional treatment program and community-based human service and rehabilitation programs to ensure that a seamless transition to the community is made and that treatment gains made while incarcerated continue after release.

The lowest recidivism rates have been found among offenders who complete inprison treatment and community-based aftercare programs as opposed to offenders who 
have completed only institutional treatment or aftercare, or no treatment at all. For example, three years after release from custody, the recidivism rate of offenders who completed the Amity therapeutic community (TC), an in-prison treatment program in California, and the TC aftercare program was $27 \%$ versus $75 \%$ of those who received treatment only or no treatment (Wexler, Melnick, Lowe, \& Peters, 1999b). Similar results have been found by researchers in other states (e.g., Martin, Butzin, \& Inciardi, 1995; Knight, Simpson, \& Hiller, 1999). The KEY/CREST program in Delaware is often cited as a model program for recovering offenders. The KEY program is a residential therapeutic community that provides intensive treatment to addicted inmates during the last 12 to 18 months of incarceration. Upon their release, offenders enter the CREST transitional TC to aid their community reintegration. CREST is a work-release program that serves male and female offenders and is followed by community-based aftercare for up to 12 months. Three years after release from prison, $69 \%$ of offenders completing CREST and aftercare were arrest-free, compared to $55 \%$ who completed CREST only, $28 \%$ of CREST dropouts, and $29 \%$ of the control group. Thirty-five percent of CREST and aftercare completers were drug-free versus $27 \%$ who completed CREST only, $17 \%$ who dropped out, and $5 \%$ of the comparison group (Martin, Butzin, Saum, $\&$ Inciardi, 1999). A 3-year outcome study of the New Vision Program in Texas by Knight et al. (1999) found that $76 \%$ of offenders who completed aftercare had not been arrested for a technical violation, versus $47 \%$ who had not participated in treatment.

With no treatment, many are destined to continue a repetitive cycle of relapse and reentry into the criminal justice system. As Vigdal and Stadler (1992) have noted, it makes good sense to consider the criminal justice system as a logical place for 
intervention. For offenders who would ordinarily not seek treatment voluntarily or have poor treatment histories, corrections-based programs can provide an opportunity to engage offenders in treatment, learn much-needed life and coping skills, serve as a springboard for participation in community-based treatment programs and, thus, put a halt to the revolving door (Peters \& May, 1992). Further, unlike traditional health care interventions that focus on one specific outcome (e.g., reduction in blood pressure, maintenance of insulin levels), substance abuse treatment can achieve favorable effects on a number of outcome measures, including health status, criminal behavior, family functioning, mental health, and employment (Cartwright, 2000; French \& Martin, 1996; Sindelar, Jofre-Benet, French, \& McClellan, 2004).

\section{Coerced Treatment, Motivation \& Treatment Outcome}

Intuition suggests that in order for treatment to be beneficial the client must acknowledge a need and desire for help. Indeed, many clinicians have been schooled in this notion. They assert that compelling someone to attend treatment violates best practice methods, invites greater resistance, and prolongs treatment unnecessarily. Coercion has traditionally been defined according to the legal status of the offender (e.g., arrested, sentenced, incarcerated; Taxman \& Messina, 2002). Yet there are other forms of coercion unrelated to legal status that motivate persons to enter treatment, such as marital dysfunction and threat of job loss. Regardless of their legal status, most persons enter substance abuse treatment because of pressure from the courts, their employer, or family members.

Some researchers (Platt, Buhringer, Kaplan, Brown, \& Taube, 1988) contend there is little to be gained by forcing an offender into treatment. Opposition to coerced 
treatment may rest on philosophical or constitutional grounds for some, while others argue against it for clinical reasons and maintain that treatment can only be effective if the person wants to change. Some might fail to realize, as Gostin (1991) has suggested, that mandatory treatment can be effective in reducing the morbidity and mortality that is associated with substance abuse.

Advocates of coerced treatment, on the other hand, (Anglin \& Maugh, 1992; Salmon \& Salmon, 1983) argue that legal coercion is as justifiable as any other motivation to enter treatment, noting that few addicts will enter and remain in treatment without some type of external motivation or pressure. Marlowe (2001) contends that coercion may increase an individual's intrinsic motivation for change, and that legal involvement may lead some clients to the realization that substance abuse is causing severe problems in their lives. Anglin (1988) and Anglin and Hser (1991) argue that legal coercion enhances public safety and benefits society as a whole by controlling drug abuse and addiction. They believe the criminal justice system should bring drug-abusing offenders into treatment.

Leukefeld and Tims (1990) and Lipton et al. (1992) note that, despite an obvious need, many drug offenders have little interest in entering treatment. Generally speaking, offenders have lower levels of motivation to enter or remain in treatment than the general (non-incarcerated) population. When asked, many minimize their drug problem or do not recognize the association between their abuse and criminal behavior. They tend to be distrustful of treatment professionals and often make no distinction between treatment staff and security personnel. Consequently, many find it difficult to view treatment staff as helpful or interested in their welfare. Many lack the interpersonal skills necessary to 
engage in group-oriented activities which comprise most of treatment, and feel threatened by the prospect of self-disclosure in a group of other inmates. This is a significant barrier to treatment success given the importance placed on the formation of positive peer relationships within TCs. Thus, many prefer to "do their own time" and forfeit opportunities for change and personal growth. Among those who do participate in treatment, many are capable of presenting favorably to their counselor(s), saying what they believe the counselor(s) wants to hear, but remain virtually unchanged around their inmate peers. In the parlance of Alcoholics Anonymous, they are able to "talk the talk," but not "walk the walk."

Evidence suggests, however, that offenders who enter treatment under legal coercion do just as well on outcome measures as offenders who enter voluntarily (Leukefeld \& Tims, 1988; Falkin, Wexler, \& Lipton, 1992; Hiller et al., 1998; Young \& Belenko, 2002). In a study by Anglin, Brecht, \& Maddahian (1989), no significant differences were found on follow-up measures of drug use and criminal behavior among three groups of heroin addicts who entered methadone maintenance treatment under low, moderate, or high coercion. DeLeon (1988) reported that posttreatment outcomes between clients entering treatment voluntarily and clients legally referred to therapeutic communities were similar. Further, client retention was greater among clients in the therapeutic community than among voluntary clients. It should be noted that these results might have been affected by the threat of sanctions if clients dropped out of treatment prematurely. To reduce this possibility, Young \& Belenko (2002) have suggested that informing clients about coercive policies and practices can improve retention even in the most coercive programs. Their analyses showed that clients in a more coercive program 
had higher retention rates than a less coercive comparison group at six and twelve months post-admission when this information was provided.

Several studies have found that clients referred to treatment by the criminal justice system stay in treatment longer and that length of treatment stay is a robust predictor of post-treatment outcomes (DeLeon, 1984; Anglin, 1988; Hubbard et al., 1988; Wexler et al., 1988; Leukefeld \& Tims, 1990; Field, 1992; Simpson, Joe, \& Brown, 1997; Simpson, Joe, \& Rowan-Szal, 1997). While the optimal length of time that offenders should remain in treatment is unclear, stays of less than ninety days have been associated with more limited treatment gains (Simpson, Joe, \& Brown, 1997). More dropouts occur within the first 90 days of treatment than at any other time (Leukefeld \& Tims, 1988; DeLeon, 1991). In the DATOS study, among cocaine addicts who completed at least ninety days of TC treatment, fifteen percent had returned to weekly cocaine use in the year following treatment, as compared to 29 percent who completed at least ninety days of outpatient treatment and 38 percent of those receiving over three weeks of inpatient treatment. Douglas (1998) cautions that treatment will be less effective if an offender's release date results in TC treatment being cut short. The same tends to be true if TC treatment is too long (e.g., more than two years). Therefore, fixing a specific completion date at the outset of treatment should be avoided. Instead, the duration of treatment should be consistent with the goals of treatment and the program's view of the change process (Douglas, 1998).

Early efforts to understand attrition have focused on patient characteristics that are associated with retention, and include factors that may be classified as either fixed or dynamic (Condelli \& DeLeon, 1993). Fixed factors include gender (Pompi \& Resnick, 
1987), age (Collins \& Allison, 1983), ethnicity (Wexler \& DeLeon, 1977), marital status (Sirotnik \& Roffe, 1977), and education level (Condelli \& Dunteman, 1993; Wexler \& DeLeon, 1977). Dynamic characteristics, on the other hand, are more amenable to change and include such factors as substance abuse (Simpson, Joe, Broome, et al., 1997), mental health problems (DeLeon, 1986; Ravndal \& Vaglum, 1991; Hiller, Knight, Rao, \& Simpson, 2002), legal involvement (Hiller et al., 1998), motivation for treatment, and level of services offered (e.g., Agosti, Nunes, Stewart, \& Quitkin, 1991). For example, Hiller, et al. (2002) found that premature dropout from a six-month residential program was associated with higher levels of criminality, mental health problems (including serious depression), prior psychiatric episode, unemployment, hostility, risk-taking, problems controlling violent impulses, abuse, and suicide. Whereas many of these studies are based on patient samples drawn from community-based facilities, comparatively few have examined predictors of premature treatment dropout within a correctional setting. In an effort to bridge this knowledge gap, Hiller, Knight, \& Simpson (1999) examined predictors of early dropout within a group of felony probationers mandated to attend a six-month residential TC program in Texas. Attrition was related to higher levels of anxiety, depression, and hostility, a history of psychiatric treatment, and lower selfefficacy.

While external motivators (e.g., court mandates, parole board referrals) have been associated with positive treatment outcomes, Anglin, Farabee, \& Prendergast (1998) advise that the role of internal motivation and treatment readiness play important roles in treatment and relapse and cannot be overlooked. The level of readiness for treatment, also referred to as internal motivation, upon admission is another reliable predictor of 
treatment retention. Clients possessing higher levels of pre-treatment readiness have been found to demonstrate higher levels of therapeutic engagement, stay longer in treatment, have better rapport with counselors, and have better treatment outcomes than those whose level of internal motivation is low (Simpson \& Joe, 1993; Simpson, Joe, \& Rowan-Szal, 1997; Broome, Simpson \& Joe, 1999). Furthermore, Joe, Simpson, and Broome (1998) found that treatment readiness is a better predictor of retention than are sociodemographic, drug use, and other background measures. A limitation of these and similar studies is that it is difficult to distinguish between treatment and selection effects (Carroll, 1997). Results may be more attributable to the successful identification of persons already primed for change and at less risk for recidivism than the effects of treatment itself. Consequently, they may not be generalizeable to other patient samples. Interestingly, in the Hiller et al. (1999) study of probationers cited above, treatment readiness and legal pressure were only marginally related to premature dropout. The authors point to previous research which indicates that probationers mandated to treatment often enter with little motivation for treatment (Farabee, Simpson, Dansereau, \& Knight, 1995), and cite efforts to increase early treatment engagement to reduce dropout (e.g. Blankenship, Dansereau, \& Simpson, 1999).

More current research has focused on the interaction between therapist, program, and patient factors and their effects on retention (DeLeon, 1991; DiClemente, 1993). Simpson (1999) notes that treatment success is not dependent upon retention per se but rather what happens (italics in original) while the person is in treatment. A considerable body of evidence indicates that the quality of the therapeutic alliance is related to therapeutic outcome (Horvath \& Symonds, 1991). The consistency of these findings has 
led some researchers (e.g., Safran \& Muran, 1995) to argue that the therapeutic alliance is the best predictor of post-treatment outcomes. Leukefeld and Tims (1988) emphasize the interaction of client factors (including internal and external motivation), nontreatment factors, and treatment itself in recovery from drug abuse. They note that external pressure can be used successfully to influence a person to enter treatment, but argue that a stable recovery cannot be maintained unless motivation and commitment are also present. Therefore, one objective of the early stage of treatment is to help the client move from a primarily external source of motivation to one that is more internal.

Readiness for treatment has been found to correlate with more favorable perceptions of counselor competence (Broome, Knight, Knight, Hiller, \& Simpson, 1997) and favorable ratings of the therapeutic relationship by counselors has also been found to increase retention (Simpson, Joe, \& Rowan-Szal, 1997). Knight et al. (2000) encourage early interventions to increase retention among offenders with low levels of internal motivation. Failure to address internal motivation for change has been associated with lower treatment retention rates (DeLeon \& Jainchill, 1986) and inferior outcomes (Simpson, Joe, \& Rowan-Szal, 1997). Knight, Hiller, Broome, and Simpson (2000) found that readiness for treatment and legal pressure are independently related to retention, but that treatment readiness was a better predictor of retention and therapeutic engagement. More research is needed to unravel the effects of coercion on motivational processes.

\section{Health issues of drug offenders}

The dramatic increase in the number of incarcerated offenders in this country over the past two decades has prompted criminal justice professionals to focus on prisoner health and the escalating costs of health care for this population. Acute and chronic 
morbidity has consistently been linked with illicit drug use. In addition to the medical consequences already mentioned that are associated with substance abuse, French, McGeary, Chitwood, \& McCoy (2000) have summarized many of the other problems to which substance also contributes. These include psychiatric conditions, neurologic complications, cardiovascular problems, and attention and memory deficits.

Although most infectious diseases are contracted in the community and not in correctional settings, once diagnosed the burden of treating them falls upon the correctional system. In response to a growing awareness of the potential health hazards of smoking and the high costs of treating smoking-related diseases, many states, including Kentucky, have adopted comprehensive or partial smoking bans in their correctional facilities. Some have also instituted smoking-cessation programs and treatment (Stashenko, 1999).

Further, Hegemin, Longshore, and Monohan (2002) note that mandatory and fixed-sentencing policies have resulted in a "graying" of the correctional population that is reflected in the increasing number of elderly and terminally ill inmates. The mean age of the prison population is increasing. Older inmates (age 45 or older) in the Hegemin et al. study (2002) were more likely than inmates 24 or younger to report health problems ( $25 \%$ versus $5 \%$ ). Like their older general population counterparts, elderly inmates are at risk for experiencing health problems such as stroke, diabetes, heart disease, and chronic respiratory problems (Dubler, 1998). They are also more susceptible to infectious diseases that are associated with chronic illnesses, institutionalization, and high-risk behaviors (Thorburn, 1995). Due to the growing population of critically ill inmates, 
nearly half of all state correctional systems were providing hospice care by the end of 1997 (National Institute of Corrections, 1998).

Women represent the fastest growing prison population in the U.S. (Henderson, 1998). Drug use and drug-related offenses among females account for much of the growth (Henderson, 1998). Similar to male inmates, female substance-abusing inmates frequently report a variety of health problems and are more likely to report poorer health status than the general population (Marquart, Brewer, \& Mullings, 1999; Ross \& Lawrence, 1998). Problems such as hepatitis, hypertension, emphysema, asthma, gynecological problems, obesity, kidney infections, dental problems, and mental health issues have all been reported (Marquart et al., 1999).

A serious health concern among women is the spread of sexually transmitted diseases, especially HIV. Sexually transmitted diseases are more commonly reported among incarcerated offenders than the general population (Hammett \& Harmon, 1999). Maruschak (1999) reported that the rate of HIV infection among male and female inmates is six times higher than in the general population of the United States. Female offenders consistently report HIV-risk behaviors including needle sharing, engaging in unprotected sex with drug-injecting partners, exchanging money for sex or drugs, and having sex with multiple partners (Cotton-Oldenburg, Martin, Jordan, Sadowski \& Kupper, 1997).

Not only do incarcerated women present with many of the same health problems as incarcerated men, they also present with unique health problems that create medical challenges to correctional administrators. Women require specialized and routine health care, such as Pap smears and mammography. They are also at risk for cervical cancer. 
Pregnant offenders often need intensive health management due to their drug use (Thorburn, 1995). Harm, Thompson, \& Chambers (1998) caution that once these women have given birth the involuntary separation between mother and child complicates the reunification process after a mother is released from incarceration and increases her risk for relapse.

Inmates also present with high rates of mental health problems. At midyear 2005 more than half of all prison and jail inmates had a mental health problem (Bureau of Justice Statistics, September, 2006). To be included in the survey, inmates must have had either a recent (past 12 months) history of mental health problems that were diagnosed or treated by a mental health professional, or experienced symptoms of a mental disorder based on criteria specified in the Diagnostic and Statistical Manual of Mental Disorders, fourth edition (DSM-IV). The percentage of jail and State inmates who met diagnostic criteria for mania, major depression, or a psychotic disorder ranged from $15 \%$ to $54 \%$. In comparison, about ten percent of persons age 18 or older in the United States general population met criteria for symptoms of a mental health disorder (National Institute on Alcohol Abuse and Alcoholism, 2001-2002). The Bureau of Justice Statistics (2006) also reports that three out of four State and local jail inmates who had a mental health problem met DSM-IV criteria for substance abuse or dependence, making it the most common cooccurring disorder among incarcerated offenders.

High rates of depression and anxiety are also reported by incarcerated women (Keaveny \& Zauszniewski, 1999; Martin, Cotton, Browne, Kurz, \& Robertson, 1995; Ross \& Lawrence, 1998; Singer, Bussey, Song, \& Lunghofer, 1995). Major affective disorders (e.g., major depression and bipolar disorder), antisocial personality disorder, 
and post-traumatic stress disorder have been commonly reported (Birecree, Bloom, Leverette, \& Williams, 1994; Ross \& Lawrence, 1998; Zlotnick, 1997). The stress of adjusting to an incarcerated setting has also been associated with suicide attempts (Liebling, 1994).

\section{Health service utilization of drug offenders}

Logic would suggest, and research confirms, that a history of drug involvement is associated with more health problems and heath service utilization (McCorkel, Butzin, Martin, \& Inciardi, 1998). A small amount of literature, based on data from urban areas, indicates that most of the health service needs among chronic drug abusers result from drug use (e.g., Bury, O’Kelly, \& Pomeroy, 1993; Selwyn, Budner, Weissman, Kleber, \& Wilber, 1994; Falkin, Prendergast, \& Anglin, 1994). This relationship is supported by the reduction in health service utilization among drug users who have been treated for their drug use (Jones \& Vischi, 1979; Holder, 1987; Holder \& Blose, 1992). However, despite a greater need for treatment, chronic drug users are less likely than non-users to receive needed treatment (Chitwood et al., 1999), except in emergency rooms where chronic drug users are 30\% more likely to use services than non-users (French, et al., 2000). In their review of five correctional systems, Hammett, Gaiter, \& Crawford (1998) reported that only $20 \%$ of substance abusing inmates received health services.

Anno (1997) reports that the per capita demand for health services is much greater among incarcerated offenders than it is for nonincarcerated individuals and, as McDonald (1995) notes, much of the demand is created by older inmates. As a consequence to the increasing demand for inmate health services, the costs of prison pharmaceuticals and medical services have surged (American Correctional Association, 1999a; 1999b; 
Thorburn, 1995). In an effort to contain correctional health care costs, the 1999 Federal Prisoner Healthcare Co-payment Act, requires federal prisoners to pay a $\$ 2$ health care service fee for each medical visit. The BOP estimated that the program would generate $\$ 1$ million in fiscal year 2000 (Government Accountability Office [GAO], 2000).

Seventy-five percent of the collected fees were deposited into the Federal Crime Victims Fund, with the remainder used to cover administrative expenses incurred in carrying out the Act. The BOP has endorsed the fee as a means to reduce frivolous medical visits and, in turn, medical staff costs. The measure is not intended to generate revenue. In its testimony to the Senate Committee on the Judiciary in May 2000, the BOP cautioned that the savings or benefits from its co-payment program and efficiency initiatives were expected to bottom out and that inmate health care costs would rise given such factors as a growing prison population and increases in pharmaceutical expenditures to treat the increasing prevalence of illnesses such as hepatitis and HIV (GAO, 2000).

Telemedicine has also demonstrated its value in curbing health care costs without necessarily sacrificing quality healthcare. Telemedicine uses telecommunications equipment to allow healthcare providers see and diagnose inmates in prisons located far from the healthcare providers' offices. In the late 1990s the National Institute of Justice and Bureau of Prisons, U.S. Department of Justice; and the U.S. Department of Defense participated in an experiment and evaluation of telemedicine. Several Federal prisons with different missions and security levels were connected via a telemedicine network. An independent evaluation indicated that prisons could improve inmate healthcare by providing remote access to more medical specialists while reducing inmate transport costs and related security management costs (McDonald, 1999). 


\section{Treatment Matching: Clinical necessity and sound economic policy}

Few would argue against the practicality of including the likelihood of benefiting from treatment in the patient selection process. Were two patients identical on all assessment measures but one, say motivation for treatment, to compete for one treatment slot, would it not make sense to admit the patient who wants help before admitting the patient who does not? After all, low motivation has been found to be associated with poor retention in a number of studies (e.g., Simpson \& Joe, 1993; Simpson, et al., 1997; Broome, at al., 1999). Some attrition can be expected. Attrition rates ranging from 25 to 90 percent have been reported (Baekeland \& Lundwall, 1975; DeLeon, 1991; Wickizer, Maynard, Atherly, \& Frederick, 1994), with the majority of dropouts occurring early in treatment (Baekeland \& Lundwall, 1975; DeLeon, 1991; Swett \& Noones, 1989; Leukefeld \& Tims, 1988).

Drug problems vary in intensity, clinical manifestation, and responsiveness to different treatment approaches (Finney \& Moos, 1986; Marlatt, 1988; McClellan \& Alterman, 1991; Hodgson, 1994). The overall efficacy of a treatment program is also an important consideration. As McClellan \& Alterman (1991) have pointed out, no program can be declared suited to a specific type of individual if the program is poorly administered or is minimally effective. No single treatment approach has been found to be effective for all patients, and a range of treatment options is necessary to address the individual needs of drug abusers (Institute of Medicine, 1990). In 1999 the National Institute on Drug Abuse (NIDA) incorporated these ideas into the Principles of Drug Addiction Treatment. They assert, in part, that treatment must be tailored to meet each 
individual's particular problems and needs. This idea is the guiding philosophy of the process of patient-treatment matching.

Hser, Polinsky, Maglione, and Anglin (1999) define patient-treatment matching as, "the selection of appropriate treatment or treatments most likely to facilitate a positive outcome in a particular individual." The emphasis on the individual within this definition affirms the recognition that no one approach is effective with all clients with drug problems. To be effective, the Principles of Drug Addiction Treatment also state that, “treatment must address the individual's drug use and any associated medical, psychological, social, vocational, and legal problems."

The assignment of patients to treatment has been based on the degree of goodness-of-fit between patient characteristics and treatment type. Patients are more likely to remain in treatment when there is a good fit between patient and program, and more likely to drop out when the fit is poor. In perhaps one of the earliest iterations of patient treatment assignment, the process of prioritization, known as triage, became familiar to generations of Americans in the comedy television series $\mathrm{M}^{*} \mathrm{~A}^{*} \mathrm{~S}^{*} \mathrm{H}$, and is employed in virtually every hospital emergency room. Triage includes an assessment to determine the severity of each patient's injuries, which are then put in descending order from most to least severe. Patients with the most severe injuries are treated first and generally receive the bulk of specialized and (usually) expensive treatment resources. The logic underlying this practice is intuitive - it is better to utilize expensive resources on patients who cannot survive without them than to waste them on patients who can.

One of the earliest matching protocols was developed in the late 1980s and was known as the Cleveland Criteria (Gastfriend \& McClellan, 1997). Later, the National 
Association of Addiction Treatment Providers and the American Society of Addiction Medicine (ASAM) created the ASAM Patient Placement Criteria (Hoffmann, Halikas, Mee-Lee, et. al., 1991). Despite its popularity, its predictive validity in terms of treatment outcome is still limited (Gastfriend \& McClellan, 1997; Melnick et al., 2001).

The importance and benefits of matching services to specific client needs has been cited in several studies. Effective matching to individual needs improves retention (Hser, et al., 1999) and treatment outcomes (McClellan, Woody, Luborsky, O’Brien, \& Druley, 1983). In a sample of clients who participated in community-based drug treatment programs, a higher level of matching of needs (e.g., alcohol use, drug use, medical, psychological, family/social, legal, employment, housing) and services (e.g., transportation, child care, language) was found to significantly predict longer treatment retention (Hser et al., 1999). Generally speaking, persons with more severe problems require more intensive treatment (Simpson, Joe, Fletcher, Hubbard, \& Anglin, 1999). Conversely, less severe problems can be treated successfully with a broader variety of treatment options, regardless of modality or level of intensity (Knight et al., 1999; Simpson et al., 1999). McClellan et al. (1983) have also shown matching to be costeffective and to improve the quality of services within existing programs.

Resources spent on dropouts can never be recouped. Priority placement, therefore, is oftentimes as important an economic policy consideration as it is a clinical issue. Managed care has been the primary driving force behind efforts to reduce the costs of treatment by limiting the length of stay in hospitals or rehabilitation facilities, and develop guidelines for matching patients to the most appropriate level of care (Gastfriend \& McClellan, 1997). Some therapeutic communities have modified their treatment 
protocols and have been restructured to provide short-term (six months or fewer) residential care for some patients (Ashery, 1985). Other techniques aimed at reducing health care utilization costs within the general population emphasize prevention, early diagnosis, and low cost effective treatment intervention (Chitwood et al., 1999).

Given the high rates of relapse and recidivism among released inmates (Marlowe, 2003; Petersilia, 1999), it is important to improve systems for linking drug-involved inmates to the most appropriate levels of care. Recognizing the unique needs of drugabusing offenders, NIDA recently released an updated set of research-based Principles targeted specifically at drug abusers who enter the criminal justice system (NIDA, July, 2006). Among them, NIDA recommends that treatment should address criminogenic factors and incorporate a system of rewards and sanctions, a la therapeutic communities, to encourage prosocial behavior and treatment participation; criminal justice supervision agents and treatment providers should collaborate in treatment planning and on the requirements for supervision and; reentry planning is essential for successful community reintegration. Further, the Principles recognize that medications are an important part of treatment for many offenders, and they recommend that strategies to prevent and treat serious medical conditions (e.g., HIV/AIDS, tuberculosis, hepatitis B and C) be included in treatment planning. However, the absence of validated and standardized clinical screening and assessment in correctional facilities makes it difficult to determine the number of inmates who need different amounts or types of treatment (Knight, Simpson, \& Hiller, 2002).

While some prison-based residential treatment programs utilize a triage model to guide their admission decisions, a "one-size-fits-all" approach to treatment raises the 
potential for directing expensive resources to less severely addicted offenders. Knight et al. (1999) and Griffith et al. (1999) suggest that priority for receiving intensive substance abuse treatment services should be assigned to those with more severe problems. Evidence that clients with a higher severity of drug use have better outcomes in residential/inpatient or more intensive or highly structured treatment comes from studies in therapeutic communities (Melnick et al., 2001), DATOS (Simpson et al., 1999), and outpatient settings (Rychtarik et al., 2000). Further, programs targeting offenders with severe addiction problems and who present at least moderate to high risk for recidivism have been shown to produce the greatest posttreatment reductions in recidivism and are more cost-effective (Andrews et al. 1990; Bonta, 1997; Gendreau, 1996).

Research does not support the placement of moderate- to high-risk offenders in less intensive treatment services (e.g., 12-Step groups, educational groups; Knight et al., 1999; Griffith et al., 1999). Consistent with this finding, Hiller, Knight, Rao, and Simpson (2002) concluded that a group of probationers in their study who reported only minor drug problems should have been referred to less intensive outpatient treatment instead of residential treatment so that residential beds could be reserved for individuals with more severe problems. Findings such as these underscore the importance of using early screening for drug and alcohol problems when making treatment decisions within correctional settings (Peters, Greenbaum, Edens, Carter, \& Ortiz, 1998). Unfortunately, however, irrelevant and incomplete information or subjective criteria are often used as the basis for making treatment referrals (Hepburn, 1994). Without proper screening, there is a greater probability of mismatching. The inappropriate referral of non-addicted or less 
severely addicted offenders to intensive treatment programs is a wasteful consumption of valuable resources that are better utilized on inmates who actually have drug problems.

\section{Description of substance abuse treatment in the Kentucky Department of}

\section{Corrections}

Substance abuse treatment within the Kentucky DOC has undergone significant modifications since the first program began in 1992. Most notably, the program has adopted a modified therapeutic community model of treatment and increased in length from two to six months. The demand for services has consistently been extremely high. Some of the demand may be attributable to an inmate's genuine desire for change; however, realistically speaking, much of the demand is assumed to derive from the high likelihood of parole $(80 \%-90 \%)$ if an inmate completes the treatment program. While many of the inmates who apply to the program require the higher structure and level of care of a TC environment, others are more appropriate for less intensive and presumably less expensive services. An unintended consequence of having only one level of treatment has been a "one-size-fits-all" approach. The screening instrument currently in use is heavily weighted toward an inmate's acknowledgment of a substance abuse problem, interest in treatment, and sufficient time left on the inmate's sentence to complete the six-month residential program before the inmate's next parole eligibility hearing. There are other potentially useful data that could be used to achieve a more efficient utilization of fiscal resources.

In a study of incarcerated drug offenders by Garrity, Hiller, Staton, Webster, and Leukefeld (2002), several preincarceration variables (demographic, past illness, past health services use, drug abuse history) predicted the utilization of physical and mental 
health services in prison. Mateyoke-Scrivner, Webster, Hiller, Staton, \& Leukefeld (2003) also report that a more extensive criminal history (as defined by number of lifetime convictions) was associated with more physical health problems and more ER visits, hospitalizations, and substance abuse treatment admissions.

Each of these variables can be assessed at prison intake and can be used to estimate future prisoner illness and demand for health services in prison. It would be useful to know if any of these variables are also associated with drug treatment completion rates. It makes little economic sense to waste resources on inmates who are not likely to complete treatment. Health information obtained at intake can also be used to direct inmates to appropriate health services they might not otherwise have been referred to at all or until much later in their incarceration.

\section{The issue of urban versus rural residency}

A dimension not yet discussed but relevant to the proposed study is that of urban-rural residence. Most of the research on the effectiveness of drug and alcohol treatment, health status, and health service utilization by drug offenders has been limited to urban or metropolitan areas. Relatively little is known about these issues as they relate to rural drug offenders. A review of the literature yielded only nine articles dating back to 1977 that specifically addressed the health problems, health service utilization, or motivation for treatment of this segment of the population. None of the studies reviewed for this study considered health status as a factor in selecting offenders for treatment visà-vis retention or dropout.

Urban-based studies (e.g. Arrestee Drug Abuse Monitoring Program) generally neglect the role of drug use among offenders in rural areas and do not reflect the 
demographic, social, and cultural differences in those areas. This has led to an inaccurate impression that rural communities are "safe havens" from drug-related crime (Herz \& Murray, 2003), when in fact the 1999 National Household Survey of Drug Use indicated that past month use of illicit drugs among 18 to 25 year olds was only $4 \%$ higher in urban areas compared to rural areas. Among persons 26 and older, the difference was only $1 \%$ (Adams, Bowman, Burke, Casson, Caviness, Coffee, Devore, Durham, Ellis, Hewitt, Hinsdale, Johnson, Myers, Penne, \& Zolon, 2001). Further, the Center on Addiction and Substance Abuse (2000) reported that rural eighth graders were 104\% more likely to use amphetamines, including methamphetamine; $50 \%$ more likely to use cocaine; $34 \%$ more likely to smoke marijuana; $29 \%$ more likely to drink alcohol; and $70 \%$ more likely to have been drunk than their urban counterparts. More recent data show that prescription drug abuse and associated crime has grown considerably in rural states (e.g., Inciardi \& Goode, 2003; Davis, Varga, Dickerson, Walsh, LeGrand, \& Lagman, 2003).

Kentucky is a rural state. The majority of the population live in non-metropolitan areas. In fact, two-thirds live in areas with populations of less than 25,000 and less than $40 \%$ of the state's incarcerated drug abusers come from urban counties (Leukefeld, 1996). Chronic drug abusers from rural and very rural areas have been shown to have significantly higher rates of lifetime drug use, as well as higher rates of drug use in the thirty days prior to their current incarceration than chronic drug abusers from urban areas (Warner \& Leukefeld, 2001). In the Garrity et al. (2002) study, rural residency was found to be one of four preincarceration variables that significantly predicted the use of inprison mental health services. Residency did not significantly predict in-prison physical health service utilization, however. 
Prior studies have examined differences between substance abusers who enter treatment and those who do not to identify factors associated with treatment seeking. In a summary of the literature on drug treatment seeking, Hartnoll (1992) concluded that drug treatment seeking is, (a) related to the seriousness of problematic drug use and, (b) "influenced by individual characteristics, environmental circumstances, and sociocultural contexts" (p. 431). In a sample of inmates from the general prison population, Warner \& Leukefeld (2001) reported that inmates from rural areas were less likely to see their drug use as problematic and were less likely to utilize drug treatment services than inmates from urban areas. The implication is that persons who do not recognize a problem will be less likely to seek help. They point to evidence suggesting that although the prevalence of substance abuse among rural and urban residents may become increasingly similar, rural and urban people differ in the types of drugs used and in their perceptions of treatment needs. In an early study by Brown, Voskuhl, and Lehman (1977), rural clients were found to be more likely than urban clients to report marijuana, amphetamines, and sedatives as their primary drug. Urban clients were more likely than rural clients to report opiates as their primary drug. Crack cocaine has also been found to be more prevalent in urban than in rural areas (Baumer, 1994).

Alcohol appears to be the most commonly abused substance among rural people, and alcohol-related problems such as arrests, hospitalization, and unintentional injuries are more common among rural populations (Kelleher, Rickert, Hardin, Pope, \& Farmer, 1992). Warner and Leukefeld (2001) suggest that the types of drugs used by rural residents may be perceived as more amenable to informal treatment and thus may decrease treatment seeking. 
Differences in treatment seeking and health service utilization have also been attributed to differences in value systems between rural and urban communities. Rural residency has been associated with suspiciousness (Sullivan, Hasler, \& Otis, 1993), doubtfulness about the effectiveness of substance abuse and mental health treatment services (Wagenfeld, Murray, Mohatt, \& DeBruyn, 1994), an emphasis on individualism and self-sufficiency (Bushy, 1997), strong family attachment, and conservatism accompanied by a tolerance for more extreme forms of behavior (Bagarozzi, 1982; Beltrane, 1978). Bagarozzi (1982) notes that greater tolerance often allows substance abuse problems to worsen by keeping them secret. Problems may surface only after a tragic event or an individual is arrested. In the lone study found that specifically addressed differences in perceived need for treatment among rural and urban arrestee's, Lo and Stephens (2002) reported that sociodemographic factors such as age and employment status exerted differential effects on an arrestee's motivation for treatment. Health status was not a factor included in the study.

Persons living in rural communities face additional barriers to treatment services. Many lack insurance and have limited income (Rhoades \& Chu, 2000). Some have no transportation (Chitwood et al., 1999). Even for those who do have transportation, health services tend to be more concentrated in urban locales, forcing rural residents to sometimes travel great distances to access services. For some, treatment may not be worth the time and traveling distance necessary to receive it.

\section{Research Questions and hypotheses}

With these issues in mind, the proposed study will examine the relationships between treatment completion and a set of demographic, motivational, and health-related 
variables among a group of rural and urban drug abusers who were incarcerated at the time of the study. The following research questions and their attendant hypotheses shall be examined:

1. Is there a significant difference between rural and urban drug offenders in their motivation for treatment?

Hypothesis: Rural offenders will report lower motivation for treatment than urban offenders.

2. Is an offender's residency (rural or urban) related to dropout from residential substance abuse treatment?

Hypothesis: Rural residency will be associated with higher dropout from treatment than urban residency.

3. Is health status related to dropout from treatment?

Hypothesis: Poorer physical and mental health status will be associated with early dropout from treatment. 


\section{CHAPTER THREE}

\section{METHOD}

\section{Program Description}

\section{History}

Substance abuse treatment within the Kentucky Department of Corrections is relatively young. The first program began in 1992 in a medium-security prison and had fifty treatment slots. The length of treatment was sixty days and was conducted in an outpatient format. In 1993 the program increased to seventy-five treatment slots and the length of treatment was expanded to ninety days. The following year the program was moved to another medium-security facility, where the number of treatment slots doubled and was located in a designated dormitory to segregate it as much as possible from the general inmate population. The number of treatment staff remained unchanged.

About the same time, a statewide community component was developed to help paroled treatment completers reintegrate more smoothly into the community. Case management staff trained in the issues facing substance-abusing offenders were hired and placed in each of the state's probation and parole districts. These staff are assigned to work with probation and parole officers, community treatment providers, and families to locate treatment services and monitor an offender's compliance with supervision and treatment requirements. Some also conduct support groups. 
Following the lead of other promising prison-based programs in the country (e.g., Wisconsin and Oregon), in 1998 the Department of Corrections' Office of Alcohol \& Other Drug Abuse Programs adopted the empirically supported TC model of treatment in each of its existing substance abuse programs, albeit in a modified fashion, given some physical limitations that prohibited full segregation from the general inmate population. Treatment staff participated in a week of intensive training to the operation of prisonbased therapeutic communities led by trainers from the Corrections Research Institute. Following this training, structural elements, treatment methods, and the unique language characteristic of TCs (e.g., structure boards, work crews, booking slips, confrontation groups, push-ups/pull-ups, etc.) were methodically incorporated into the daily treatment regimen over the course of many months. Since that initial training, the treatment staff has participated in other training opportunities as resources have permitted. At the time that data were collected, there were four prison-based TC programs for adult male inmates in operation.

\section{Location}

Each of the prison-based TC programs is housed in a designated living unit. One program is separated from the remainder of the facility by a gated fence. Complete segregation from the general inmate population is not possible; however, $\mathrm{TC}$ residents attend a number of supervised functions and services together to minimize contact with non-program inmates (e.g., meals, recreation, religious services, canteen, pill call, etc.). Unauthorized contact with general population inmates is prohibited. A variety of sanctions may be applied for rule violations. 
Within each living unit a centrally located control center affords correctional officers visibility in most of the living areas. Depending on the facility's space limitations, treatment staff either share office space in the living unit or occupy offices in a separate building. The majority of treatment activities are conducted in the living unit; some may be held in areas designated for other inmate programs. Recreational activities can be conducted in an enclosed yard contiguous to the living unit or at specially arranged times in the prison's gymnasium.

\section{Therapeutic Personnel, Programming and Treatment Issues}

The majority of the therapeutic community staff is composed of paraprofessionals with varying degrees of experience with criminal justice and AODA clients. To the extent possible, individual staff duties are matched to their strengths. For example, a staff member with a master's degree in psychology may be assigned to facilitate the majority of process groups, whereas someone with no such experience may focus on conducting psychoeducational groups. All have at least a bachelor's degree in a behavioral science, and some have state certification as professional substance abuse counselors. The average staff to inmate ratio is $1: 22$.

The minimum length of treatment is six months. Progress is dependent upon an inmate's motivation, compliance with TC rules and expectations, and observable changes in attitudes and behavior that are maintained over the course of treatment. Treatment may be extended or terminated for a variety of reasons, e.g., institutional/program rule infractions, failure to make anticipated treatment gains, medical, etc. Termination from treatment is viewed as a measure of last resort. Treatment staff will work with an inmate 
to avoid termination. For example, noncompliant inmates may be placed on probationary status and asked to sign a specialized behavioral contract for a specified period of time.

Programming is conducted in a group format and is divided into three phases. The Orientation phase is designed to engage offenders in treatment by educating them about the process of treatment and the TC model. Offenders become familiarized with TC rules and expectations, and are assigned to various work crews. Primary treatment occurs in Phase Two. Education about the deleterious effects of drugs and alcohol, and skills training in basic life management (e.g., communication skills, stress management, anger management, leisure skills, time management) and problem-solving are provided. A central focus in this phase is on correcting thinking errors that lead to misinterpretations of situations and poor decision-making (Samenow \& Yochelson, 1984). The purpose of the final phase is to help the offender make as smooth a transition as possible from an incarcerated to community setting. Relapse prevention (Marlatt, 1985) and reentry planning are the foci of this stage. Offenders are taught how to recognize and deal with the warning signs and high-risk situations that lead them to relapse. Final preparations for home and job placement are made with the assistance of an institutional parole officer.

\section{Participants}

This analysis is part of a larger project by the University of Kentucky's Center on Drug \& Alcohol Research to examine the health services utilization of incarcerated drug abusers when they return to the community after incarceration. The study was funded by Grant No. RO1 DA11309 from the National Institute on Drug Abuse (Carl G. Leukefeld, principal investigator). A total of 661 male participants from three medium-security and one minimum-security prisons in Kentucky were involved in the original study sample, 
and included general population inmates with a history of substance abuse treatment and general population inmates with no such history. Offenders with no substance abuse treatment history were excluded from this study because they had no score on the outcome variable of interest (i.e. treatment dropout). This exclusion resulted in a final sample of 247 participants.

\section{Demographic Variables}

Demographic variables used in this study included race/ethnicity, age, highest grade completed, marital status, employment status in the last three years prior to incarceration, and residency.

Race/Ethnicity. Offenders were divided into two groups (African American, White/Caucasian). A third group (Other) was eliminated from the analyses because of its low frequency $(n=6)$. Half $(50 \%)$ of the participants in the sample were White/Caucasian.

Age/Highest grade completed. Both of these were treated as continuous variables. Age represented the age at which the offender entered treatment. The average age was 31.3 years. The average number of years of education was 11.6.

Marital status. Three categories of marital status were used. Categories for Married and Single persons were treated separately. Divorced/Separated/Widowed were collapsed into a single category. More than half (55\%) of the sample were single. Married offenders accounted for $19 \%$ of the sample; $26 \%$ were divorced, separated, or widowed.

Employment status. Four employment categories were used including Full-time, Part-time, Unemployed, and Not in Work Force. The Part-time category included offenders who worked regular part-time hours and those who worked irregular part-time 
hours. Additionally, because of their low individual frequencies, offenders who identified themselves as students, retired/disabled, involved in service only activities, and residing in a controlled environment were collapsed into a fourth variable coded as "Not in Work Force." Forty-five percent had been employed on a full-time basis for three years prior to their incarceration.

Residency. Locator data were collected on all subjects that included the city or town that those respondents considered their home. These areas were divided into urban and rural based on population counts taken from the 1990 U.S. Census. An area was defined as urban if it had a 1990 census population of 50,000 or more, or if the population was within a census-identified urbanized area, regardless of the population size. An area was defined as rural if its census population was 49,999 or less and was not within an urbanized area. The selection of 50,000 as the cut point was based on the U.S. Census Bureau's definition of "metropolitan area" and has been used in previous studies on substance-related issues and rural residency (Leukefeld et al., 2002; Warner \& Leukefeld, 2001). Nearly two-thirds (64\%) of the sample were from urban areas; the remaining $36 \%$ were from rural locales. A summary description of the sample can be found in Table 1.

\section{Subject Selection}

Study eligibility criteria were as follows: (1) being a drug user, defined as having used drugs at least three times per week during the year prior to incarceration; (2) having had at least three months of not being incarcerated before the current incarceration; (3) having an interest in participating in the study and; (4) having no self-reported past or present charges of rape or murder. This was an established criterion for program 
admission and is based on the idea that TCs have historically not treated clients whose primary problem is not substance abuse and who, consequently, require special strategies to address. For example, sex offender treatment is highly specialized and requires training that most of the staff of the TC program did not have. Enrollment in the project was voluntary and confidentiality was strictly observed. All participants were given a monetary incentive for their participation.

Table 1. Sample Description $(\mathrm{N}=247)$

\begin{tabular}{|l|c|c|c|}
\hline Characteristic & $\mathrm{N}$ & $\%$ & $\begin{array}{c}\text { Mean } \\
\text { (SD) }\end{array}$ \\
\hline Male & 247 & 100 & \\
\hline Race/Ethnicity & & & \\
\hline African American & 117 & 47 & \\
\hline White/Caucasian & 124 & 50 & \\
\hline Other & 6 & 3 & \\
\hline Age & 247 & $-\cdots$ & 31.3 \\
\hline Marital Status & & & $(7.11)$ \\
\hline Married & 46 & 19 & \\
\hline Single & 136 & 55 & \\
\hline Divorced/separated/widowed & 65 & 26 & \\
\hline Highest Grade Completed & 247 & $-\cdots$ & 11.6 \\
\hline Place of Residence & 158 & 64 & \\
\hline Rural & & & \\
\hline Urban & & 36 & \\
\hline
\end{tabular}




\begin{tabular}{|l|c|c|c|}
\hline Employment past 3 years & & & \\
\hline Full-time & 111 & 45 & \\
\hline Part-time & 48 & 20 & \\
\hline Unemployed & 27 & 11 & \\
\hline Not in Work Force & 58 & 24 & \\
\hline
\end{tabular}

Potential subjects were identified monthly through prison-generated lists of inmates who were scheduled to meet with the parole board in the following three months. These inmates received letters that described the purpose of the study and provided a time for a general study screening. Group screenings were used to determine individual eligibility and to obtain consent to participate in the study. The screening incorporated a four-page questionnaire to ascertain interest and eligibility, and took about ten minutes to complete.

Between the months of April 1998 and July 1999, eligible inmates who were scheduled for parole hearings received study recruitment letters. Interested candidates attended a screening to learn more about the study and to ensure their eligibility. Within two weeks following screening, eligible subjects were provided with informed consent that emphasized the voluntary nature of the study and the protection of confidentiality under the federal guidelines of the Certificate of Confidentiality. This was intended to encourage truthful responses and reduce threats to the study's internal validity created by the self-report method of data collection. Additionally, a random sample of self-reported data was cross-validated by comparing it to institutional records. After informed consent was obtained, participants were interviewed in private, face-to-face settings. Neither treatment nor security staff were present. Interviewers were given in-depth training to 
thoroughly acquaint them with the questionnaire and in the accurate coding of responses. Training included practice with standardized subjects, interview observations, and random observations of data collection, and was intended to improve inter-rater reliability in response coding. Additionally, interviewers received an orientation to the ethical and clinical issues prevalent in the criminal justice population. Extensive baseline data were collected on both lifetime and current health problems and treatment, including drug and alcohol problems. The interviewer asked each question and recorded individual responses on the structured interview instrument. Components of the structured interview included the University of Miami Health Services Research Instrument (HSRI) (Chitwood, McBride, French, \& Comerford, 1999), the Addiction Severity Index (ASI) (McClellan, Luborsky, O'Brien, \& Woody, 1980), and the Texas Christian University Motivation Assessment (Simpson \& Joe, 1993).

\section{Experimental Design}

\section{Dependent Variable}

The outcome criterion was a dichotomously scored measure (completed treatment $=1$; did not complete $=0$ ), which was based on discharge information obtained from treatment program records and on self-report from the follow-up questionnaire. Several reasons could account for an offender being discharged prematurely from the program including expulsion for violating program and/or institutional rules, severe psychological disturbance, serious medical problem, transfer to another correctional facility, or voluntary withdrawal. The majority of program participants ( $92 \%$ or $228 / 247)$ completed the treatment program. Nineteen ( $8 \%$ ) dropped out of treatment prematurely. 


\section{Independent Variables}

Motivation for Treatment. An offender's motivation for treatment was measured using the TCU Treatment Motivation Assessment developed by Simpson \& Joe (1993), and consists of three subscales (i.e., Problem Recognition, Desire for Help, Treatment Readiness).

Problem Recognition. The problem recognition scale (coefficient alpha $=.87$, see Table 2) of the TCU Treatment Motivation Assessment (Simpson \& Joe, 1993) was used to assess the degree to which offenders recognized that their drug use was causing problems in their life. The scale is comprised of nine items and includes such statements as "Your drug use was a problem for you," and "Your drug use caused problems with family or friends." Offenders were asked to rate their endorsement of each item on a Likert scale (ranging from $0=$ "strongly disagree" to $4=$ "strongly agree") for the year prior to their incarceration. A composite index score was obtained by calculating the mean score for the nine items in the scale $($ mean $=2.07 ;$ standard deviation $=1.04)$.

Desire for Help. As shown in Table 2, the TCU Motivation Assessment (Simpson \& Joe, 1993) desire for help subscale (coefficient alpha $=.74$ ) asked respondents to rate their endorsement of statements such as "You need help in dealing with your drug use" and "It is urgent that you find help immediately for your drug use" on a Likert scale (range $0=$ strongly disagree to $4=$ strongly agree). The mean response to each of the seven subscale items was used to calculate a desire for help composite index score (mean = 1.97; standard deviation $=.98$ ). Generally speaking, there was a considerable degree of ambivalence associated with offenders' desire for help for their substance abuse problems. 
Treatment Readiness. The treatment readiness scale (coefficient alpha $=.52$ ) from the TCU Motivation Assessment (Simpson \& Joe, 1993) asks respondents to assess their level of preparedness for treatment on a Likert scale ranging from 0 (strongly disagree) to 4 (strongly agree). Of the original seven items contained in the scale, three were used to compute a treatment readiness composite index score because they were the items included in the survey. This was due to the fact that these three items Offenders were asked whether they felt that they had too many responsibilities to be in the treatment program, whether treatment programs were too demanding for them, and whether treatment may have been their last chance to solve their drug problem. Calculating the average response to each item provided a composite index score for treatment readiness $(\mathrm{M}=1.8 ; \mathrm{SD}=1.5)$. Because the last item listed above had a low correlation with the others, it was excluded from further analyses. This resulted in a coefficient alpha $=.65$. Table 2. TCU Motivation

\begin{tabular}{|l|c|c|}
\hline Item/Scale & Mean & $\begin{array}{c}\text { Standard } \\
\text { Deviation }\end{array}$ \\
\hline Problem Recognition (Alpha $=.87)^{1}$ & 2.07 & 1.04 \\
\hline Was a problem for you & 1.8 & 1.6 \\
\hline Was more trouble than it was worth & 2.0 & 1.5 \\
\hline Caused problems with the law & 2.6 & 1.4 \\
\hline Caused problems in thinking or work & 2.2 & 1.4 \\
\hline Caused problems with family or friends & 2.4 & 1.4 \\
\hline Caused problems in finding or keeping a job & 1.7 & 1.6 \\
\hline Caused problems with your health & 1.3 & 1.4 \\
\hline Caused your life to become worse and & 2.5 & 1.5 \\
\hline
\end{tabular}




\begin{tabular}{|l|c|c|}
\hline worse & & \\
\hline $\begin{array}{l}\text { Was going to cause your death if you didn't } \\
\text { quit }\end{array}$ & 2.0 & 1.7 \\
\hline Desire for Help (Alpha =.74) & 1.97 & .98 \\
\hline Needed help in dealing with your drug use & 2.0 & 1.6 \\
\hline It was urgent that you find help immediately & 1.2 & 1.5 \\
\hline $\begin{array}{l}\text { You were tired of the problems caused by } \\
\text { drugs }\end{array}$ & 2.2 & 1.6 \\
\hline $\begin{array}{l}\text { You would have given up your friends and } \\
\text { hangouts }\end{array}$ & 1.5 & 1.5 \\
\hline $\begin{array}{l}\text { You could have quit using drugs without } \\
\text { help }\end{array}$ & 1.8 & 1.7 \\
\hline Your life went out of control & 2.2 & 1.5 \\
\hline You wanted to straighten your life out & 2.8 & 1.4 \\
\hline Treatment Readiness (Alpha =.65) & 1.8 & 1.5 \\
\hline $\begin{array}{l}\text { You had too many responsibilities to be in } \\
\text { treatment }\end{array}$ & 1.7 & 1.7 \\
\hline $\begin{array}{l}\text { Treatment programs were too demanding } \\
\text { for you }\end{array}$ & 2.0 & 1.8 \\
\hline
\end{tabular}

The prompt, "In your opinion how often did you feel your drug use..." was used for problem recognition items.

Mental Health Problems. Two composite measures of mental health problems were created using the Addiction Severity Index (see Table 3). The ASI (McClellan et al., 1980 ) is a structured interview designed to assess demographic information and personal histories in several areas of drug abuse and health. Reliable and valid measures of problem severity for both drug and alcohol abusers have been found using ASI ratings, and they have also been found to be sensitive to changes occurring during the treatment 
process (Kosten, Rounsaville, \& Kleber, 1983; McClellan, Luborsky, O'Brien, Woody, \& Druley, 1982). The first composite, lifetime psychological problems (range 0-7; Alpha $=.72$ ) was constructed by summing ASI items that asked respondents if they had ever experienced in their lifetime serious depression, serious anxiety, hallucinations, difficulty understanding, concentrating, or remembering for at least two weeks, difficulty controlling violent behavior, serious thoughts of suicide, or attempted suicide. The average score on this measure was 1.8 (standard deviation $=1.81)$. The second composite $($ Alpha $=.63)$ reflected these symptoms in the 30 days prior to incarceration. The average score on this measure was .97 (standard deviation $=1.31$ ). In addition to these symptoms several other items were used to measure psychological health. These included how many times an offender had been treated in an inpatient $($ mean $=.35 ;$ standard deviation $=1.07)$ or outpatient (mean $=.62 ;$ standard deviation $=2.3)$ treatment setting for mental health problems, and the percentages of offenders who had been prescribed any medication for any psychological/emotional problem in their lifetime or in the 30 days prior to their incarceration ( $24 \%$ and $5.3 \%$, respectively). Finally, offenders were asked how many days in the 30 days prior to their incarceration they had experienced these psychological or emotional problems $($ mean $=6.0 ;$ standard deviation $=10.3)$.

Responses to questions related to an offender's use of particular substances (e.g., type, age at first use, recent/lifetime usage patterns) were not included in this study because it was assumed that offenders had self-reported a substance abuse problem, and because of the obvious emotional/psychological problems that are associated with the abuse of alcohol and drugs (Garrity et al., 2002). 
Table 3. Mental health composites from the Addiction Severity Index

\begin{tabular}{|c|c|c|c|c|}
\hline \multirow[b]{2}{*}{ Mental health item } & \multicolumn{2}{|c|}{ Lifetime (alpha $=.63$ ) } & \multicolumn{2}{|c|}{ Last 30 days (alpha $=$ ) } \\
\hline & Percent & Item-total correlation & Percent & Item-total correlation \\
\hline \multicolumn{5}{|l|}{$\begin{array}{l}\text { Have you had a significant period in which } \\
\text { you have... }\end{array}$} \\
\hline $\begin{array}{l}\text { Experienced serious depression for at } \\
\text { least } 2 \text { weeks }\end{array}$ & 35.2 & .53 & 17.8 & .54 \\
\hline $\begin{array}{l}\text { Experienced serious anxiety or tension } \\
\text { for at least } 2 \text { weeks }\end{array}$ & 34.0 & .43 & 23.1 & .45 \\
\hline Experienced hallucinations & 6.9 & .42 & 2.8 & .32 \\
\hline $\begin{array}{l}\text { Experienced trouble understanding, } \\
\text { concentrating, or remembering for at } \\
\text { least } 2 \text { weeks }\end{array}$ & 25.1 & .44 & 17.0 & .36 \\
\hline $\begin{array}{l}\text { Experienced trouble controlling violent } \\
\text { behavior }\end{array}$ & 41.7 & .19 & 24.7 & .16 \\
\hline Experienced serious thoughts of suicide & 21.9 & .60 & 8.9 & .45 \\
\hline Attempted suicide & 17.0 & .54 & 3.2 & .30 \\
\hline
\end{tabular}

IThe stem for the last 30 day mental health items was, "Did these problems also occur in the 30 days prior to your incarceration?" 
Physical Health Problems. Self-reported lifetime rates of physical health problems were obtained on each of 13 physiological systems or problem areas (including urogenital, respiratory, trauma/physical injury, musculoskeletal, hepatic, cardiovascular, gastrointestinal, neurological, integumentary, eye/ear/nose/throat, communicable disease, dental, and other), using the HSRI. The HSRI (Chitwood et al., 1999) includes questions from the Ryan White Health Care Utilization Supplement and the National Health Utilization Survey as well as other questions developed by the University of Miami Health Services Research Center. Prior research has used the HSRI to assess self-reported health problems and to explore the relationships between chronic drug use and health care service utilization (Chitwood, McBride, Metch, Comerford, \& McCoy, 1998; Chitwood et al.,1999). It was used in this study to measure self-reported medical and emotional/psychological status. Two composite physical health problems indices (range $=$ 0 to 13 , see Table 4) were calculated. The first was derived by adding the total number of health problems a respondent indicated they had experienced in their lifetime $(M=4.7$; $\mathrm{SD}=2.04)$. A similar index was calculated for the number of health problems a respondent had experienced in the year prior to their incarceration $(M=2.0 ; \mathrm{SD}=1.8)$. Table 4. HSRI physical health problems

\begin{tabular}{|l|c|c|}
\hline Physical health problems & \% Lifetime & $\begin{array}{c}\text { \% Year prior to } \\
\text { incarceration }\end{array}$ \\
\hline Urogenital & 7.3 & 2.4 \\
\hline Respiratory & 43.9 & 19.5 \\
\hline Trauma/physical injury & 89.5 & 33.6 \\
\hline Musculoskeletal & 38.9 & 25.5 \\
\hline Hepatic & 10.9 & 2.4 \\
\hline
\end{tabular}




\begin{tabular}{|l|c|c|}
\hline Cardiovascular & 27.5 & 10.5 \\
\hline Gastrointestinal & 23.9 & 16.6 \\
\hline Neurological & 32.8 & 21.1 \\
\hline Integumentary & 22.3 & 9.3 \\
\hline Eye/ear/nose/throat & 28.9 & 13.8 \\
\hline Communicable disease & 40.9 & 6.9 \\
\hline Dental & 89.9 & 34.8 \\
\hline Other & 10.1 & 4.0 \\
\hline
\end{tabular}

\section{Data Analysis}

The database was compiled and is maintained by the University of Kentucky's Center on Drug \& Alcohol Research. Using a statistical procedure described by Hiller et al. (1999), a two-stage analytic plan was used to identify which of the background predictors described above were significantly associated with treatment completion. In the first stage, a series of exploratory Pearson correlations were used to examine simple relationships between each of the predictor variables and the outcome variable. In the second stage, factors that were found to be significantly associated with treatment completion (with a corresponding alpha level of $p<.25$ ) were loaded into a multivariate model using a stepwise logistic regression procedure described by Hosmer \& Lemeshow (2000). Table 5 below shows the correlation matrix for each of the 19 variables that were included in the study. Since one of the main uses of logistic regression is to calculate the probability of success over the probability of failure by creating a model that includes all of the predictor variables that are useful in predicting the response variable, it was an 
appropriate choice for the statistical analysis. The following analysis produced the most efficient, parsimonious set of variables that predicted premature treatment dropout. 
Table 7. Correlation matrix

\begin{tabular}{|c|c|c|c|c|c|c|c|c|c|c|c|c|c|c|c|c|c|c|c|}
\hline Variable & Grad & Race & Age & Mar & Educ. & Res. & Empl & $\begin{array}{l}\text { Prob: } \\
\text { Rec }\end{array}$ & $\begin{array}{l}\text { Desit } \\
\text { Help }\end{array}$ & $\begin{array}{l}\text { Tx } \\
\text { Ready }\end{array}$ & $\begin{array}{l}\text { ASI } \\
\text { mb- } \\
\text { life }\end{array}$ & $\begin{array}{l}\text { ASI } \\
\text { mh_ } \\
30 \\
\end{array}$ & $\begin{array}{l}\text { \#Psy } \\
\text { Hosp }\end{array}$ & $\begin{array}{l}\text { \#Psy } \\
\text { outpt }\end{array}$ & $\begin{array}{l}\text { Psy } \\
\text { meds }\end{array}$ & $\begin{array}{l}\text { Psy } \\
\text { Meds } \\
30 \\
\end{array}$ & $\begin{array}{l}\text { \#Days } \\
\text { 30day } \\
\text { prior }\end{array}$ & $\begin{array}{l}\text { Phys } \\
\text { health } \\
\text { life }\end{array}$ & $\begin{array}{l}\text { Phys } \\
\text { Past } \\
\text { year }\end{array}$ \\
\hline Race & -.09 & $\cdots$ & -.02 & .05 & -.00 & .12 & .07 & .02 & .11 & -.08 & .03 & -.03 & -.03 & -.05 & .03 & .00 &. .07 & .07 & -.01 \\
\hline Age & .12 & -.02 & $\cdots$ & -.10 & .05 & .07 & -.07 & .20 & .28 & .01 & -.02 & .01 & -.05 & .06 & -.07 & .06 & -.05 & .24 & \begin{tabular}{|l|}
.10 \\
\end{tabular} \\
\hline Marital & .03 & -.05 & -.10 & $\cdots$ & .06 & .03 & .03 & -.04 & -.09 & $\begin{array}{l}.09 \\
\end{array}$ & .03 & .07 & .14 & .02 & -.12 & .06 & -.01 & .01 & .02 \\
\hline Education & .02 & .00 & .05 & .06 & ---- & .13 & -06 & -.11 & -.05 & -.07 & -.00 & .01 & .01 & .01 & .07 & .08 & .05 & .07 & .08 \\
\hline Employmt &. .09 & .07 & -.07 & .03 & .06 & .03 & $\cdots$ & .02 & -.02 & -.06 & .02 & -.00 & .17 & .18 & .04 & .05 & .05 & $.03^{\circ}$ & -.03 \\
\hline $\begin{array}{l}\text { Problem } \\
\text { Recognition }\end{array}$ & .08 & .02 & .20 & -04 & -.11 & .11 & .02 & $\cdots$ & .73 & .27 & .19 & .18 & 04 & .10 & .14 & .06 & .13 & .27 & .27 \\
\hline $\begin{array}{l}\text { Desite for } \\
\text { help. }\end{array}$ & .08 & .11 & .28 & -.09 & -.05 & .14 & -.02 & .73 & --- & .20 & $\begin{array}{l}.08 \\
\end{array}$ & .07 & -.04 & .06 & .09 & 07 & 07 & .30 & .23 \\
\hline $\begin{array}{l}\text { Treatment } \\
\text { Readiness }\end{array}$ & .08 & -.08 & .01 & .09 & -.07 & .07 & .06 & .27 & .20 & $\cdots$ & .21 & .18 & .04 & .02 & .08 & .04 & .06 & .17 & .15 \\
\hline $\begin{array}{l}\text { \#Psych } \\
\text { outpt }\end{array}$ & .01 & -.05 & .06 & -.02 & -.01 & .06 & .18 & .10 & .06 & .02 & .30 & .34 & .60 & $\ldots$ & .41 & .45 & .35 & .08 & .12 \\
\hline Psymeds & -.02 & .03 & .07 & -.12 & .07 & -.06 & .04 & .14 & .09 & .08 & .56 & .44 & .47 & .41 & $\cdots$ & .43 & .48 & .19 & .32 \\
\hline Psymed 30 & 07 & .00 & .06 & 06 & .08 & $\begin{array}{c}-.09 \\
\end{array}$ & -.05 & .06 & .07 & -.04 & .34 & .40 & .37 & .45 & .43 & $\cdots$ & .36 & .14 & .25 \\
\hline $\begin{array}{l}\text { HDays } 30 \\
\text { days prior }\end{array}$ & .03 & -.07 & -.05 & -.01 & .05 & -.12 & .05 & .13 & .07 & .06 & .57 & .66 & .41 & .35 & .48 & .36 & $\cdots$ & .26 & .29 \\
\hline $\begin{array}{l}\text { Physhealth- } \\
\text { life. }\end{array}$ & .02 & .07 & .24 & .01 & .07 & .05 & .03 & .27 & .30 & .17 & .36 & .25 & .04 & .08 & .19 & .14 & .26 & $\cdots$ & .66 \\
\hline $\begin{array}{l}\text { Physhealth } \\
\text { past year }\end{array}$ & .02 & -.01 & .10 & .02 & .08 & -.13 & -.03 & .27 & .23 & .15 & .41 & .35 & .15 & .12 & .32 & .25 & .26 & .66 & - \\
\hline 5 & & & & & & & & & & & & & & & & & & & \\
\hline
\end{tabular}




\section{CHAPTER FOUR}

\section{RESULTS}

The following data analyses were performed to assess the degree to which dropout from residential substance abuse treatment was related to an offender's residency, motivation, and health status. Compared to incarcerated drug offenders from urban communities, far less is known about rural drug offenders and how these factors affect dropout from treatment. Subjects were selected from six-month residential substance abuse treatment programs in four Kentucky prisons. It was hypothesized that: 1) rural offenders would report lower motivation for treatment than urban offenders; 2) rural residency would be associated with higher dropout from treatment, and; 3) poorer physical and mental health would also be associated with early departure from treatment.

\section{Rural-Urban Comparison}

Table 6 shown below presents the comparison of rural and urban offenders on each of the demographic, motivation, and health status variables used in this study. Following the analytical strategy used by Hiller et al. (1999), a series of chi-square and ANOVA analyses were performed to compare rural and urban drug offenders on their sociodemographic background, treatment motivation, mental health, and physical health. With respect to the first hypothesis, the analyses showed that there were differences in treatment motivation between rural and urban offenders. Specifically, rural offenders had 
a significantly lower desire for help $[\mathrm{t}(244)=-2.27, \mathrm{p}<.05]$. Scores on problem recognition and treatment readiness were not significantly different.

No statistically significant differences were found with respect to each of the mental health indices. For example, when comparing ASI composites for lifetime and past thirty day mental health symptoms, no significant differences were found $[\mathrm{t}(245)=$ $.82, \mathrm{p}=\mathrm{ns} ; \mathrm{t}(244)=1.3, \mathrm{p}=\mathrm{ns}$, respectively]. Similarly, there were no differences in the percentage of individuals who had used psychiatric medication in their lifetime $[\times 2(1, n=$ $244)=1.98, p=n s]$ or in the thirty days prior to incarceration. $[x 2(2, n=244)=2.05, p=$ ns]

With regard to physical health problems, no significant differences were found between rural and urban offenders on the lifetime physical health composite $[\mathrm{t}(243)=$ $.71, \mathrm{p}=\mathrm{ns}]$. A significant difference was found, however, on the composite measuring the number of health problems an offender reported that they had experienced in the year prior to incarceration $[t(243)=2.01, p<.05)$. Specifically, rural offenders reported an average of $2.3(\mathrm{SD}=1.9)$ physical health problems versus an average of $1.8(\mathrm{SD}=1.7)$ reported by urban offenders $(\mathrm{p}<.05)$.

Table 6. Comparison of Rural and Urban Offenders in Prison-based Substance Abuse Treatment $(\mathrm{N}=247)$

\begin{tabular}{|c|c|c|}
\hline Characteristic & $\begin{array}{l}\text { Rural } \\
\mathrm{n}=89\end{array}$ & $\begin{array}{l}\text { Urban } \\
\mathrm{n}=158\end{array}$ \\
\hline$\%$ Male & 100 & 100 \\
\hline \% Race/Ethnicity & & \\
\hline African American & $28(n=25)$ & $58(n=92)$ \\
\hline
\end{tabular}




\begin{tabular}{|c|c|c|}
\hline White/Caucasian & $70(n=62)$ & $39(n=62)$ \\
\hline Other & $2(n=2)$ & $3(n=4)$ \\
\hline Age & $30.6(6.2)$ & $31.6(7.6)$ \\
\hline \multicolumn{3}{|l|}{$\%$ Marital Status } \\
\hline Married & 7 & 15 \\
\hline Single & 17 & 37 \\
\hline Divorced/separated/widowed & 10 & 15 \\
\hline Highest Grade Completed & 8.1 & 13.2 \\
\hline \multicolumn{3}{|l|}{ Employment past 3 years } \\
\hline Full-time & 17 & 28 \\
\hline Part-time & 8 & 12 \\
\hline Unemployed & 2 & 9 \\
\hline Not in Work Force & 9 & 15 \\
\hline \multicolumn{3}{|l|}{ TCU Motivation Scale } \\
\hline Problem Recognition & $1.9(1.0)$ & $2.2(1.06)$ \\
\hline Desire for Help* & $1.8(.90)$ & $2.1(1.0)$ \\
\hline Treatment Readiness & $1.7(1.5)$ & $2.1(1.0)$ \\
\hline \multicolumn{3}{|l|}{ Mental health } \\
\hline ASI Composite Lifetime & $1.9(1.9)$ & $1.7(1.8)$ \\
\hline $\begin{array}{l}\text { ASI Composite } 30 \text { days prior to } \\
\text { incarceration }\end{array}$ & $1.1(1.4)$ & $.89(1.3)$ \\
\hline Number of inpatient treatment episodes & $.53(1.5)$ & $.24(.70)$ \\
\hline Number of outpatient treatment episodes & $81(2.8)$ & $.51(2.1)$ \\
\hline$\%$ psychiatric medication lifetime & 27 & 22 \\
\hline$\%$ psychiatric medication 30 days prior & 8 & 4 \\
\hline
\end{tabular}




\begin{tabular}{|l|c|c|}
\hline to incarceration & & \\
\hline $\begin{array}{l}\text { Number of psychiatric problems 30 days } \\
\text { prior to incarceration }\end{array}$ & $7.5(11.1)$ & $5.2(9.7)$ \\
\hline \multicolumn{1}{|c|}{ Physical health } & $4.5(2.1)$ & $4.7(2.0)$ \\
\hline $\begin{array}{l}\text { HSRI Physical Health Composite } \\
\text { Lifetime }\end{array}$ & $2.31(1.88)$ & $1.8(1.71)$ \\
\hline $\begin{array}{l}\text { HSRI Physical Health Composite } 30 \\
\text { days prior to incarceration* }\end{array}$ & \\
\hline
\end{tabular}

\section{Multivariate Model}

A stepwise logistic regression model for determining which set of factors best predicted treatment dropout used all independent variables found to be statistically significant in the first analytic step (see Table 7). Included in the final model were race, age, residency, employment, treatment motivation (i.e., problem recognition, desire for help, and treatment readiness), and lifetime mental health. The final results indicated that rural offenders were 3.6 times more likely to drop out of treatment early than their urbanbased counterparts $(b=1.27, \underline{p}<.05)$ Age was also related to premature dropout. For every one year increase in age, there was an $8 \%$ increase in the probability that someone would drop out of treatment $(b=.08, \mathrm{p}<.10)$. None of the other factors were significantly related to dropping out of treatment early. 
Table 7. Summary of Stepwise Logistic Regression Model for Predicting

Treatment Dropout

\begin{tabular}{|c|c|c|c|}
\hline Predictor & $b$ & $\mathrm{SE}$ & Odds Ratio \\
\hline White & 1.7 & 1.4 & 5.4 \\
\hline Black & 28 & 1.4 & 1.3 \\
\hline Age $^{\dagger}$ & .08 & .05 & 1.1 \\
\hline Residency* & 1.27 & .55 & 3.6 \\
\hline Full-time & .52 & .64 & 1.7 \\
\hline Part-time & 44 & .72 & 1.5 \\
\hline Unemployed & 1.2 & .94 & 3.3 \\
\hline Motivation & -.13 & .35 & 88 \\
\hline $\begin{array}{l}\text { Desire for } \\
\text { help }\end{array}$ & .35 & .40 & 1.4 \\
\hline $\begin{array}{l}\text { Readiness } \\
\text { for } t x\end{array}$ & .03 & .19 & 1.0 \\
\hline Mental_life & 13 & .18 & 1.1 \\
\hline
\end{tabular}




\section{CHAPTER FIVE}

\section{DISCUSSION}

A considerable body of research has established the prevalence of substance abuse, physical health problems, and mental health problems among prisoners, and there is now a growing body of data focusing on the health service utilization of drug-involved offenders. Additionally, motivation for treatment has been shown repeatedly to improve treatment retention rates and is associated with better outcomes, vis-à-vis recidivism and relapse. Most of these findings are based on samples taken from urban populations. Relatively little is known about rural drug offenders and the similarities and differences they may have with their urban counterparts and the impact of health status on treatment completion.

This study examined differences in treatment motivation, mental health problems, and physical health problems within a group of male drug offenders enrolled in a prisonbased substance abuse treatment program. Of interest was whether dropout from treatment was related to these factors and, more specifically, whether there were significant differences that were associated with being from a rural or urban area. Specific attention was given to extending the corrections-based drug treatment literature by focusing on an offender's residency prior to coming to prison. It was hypothesized that rural drug offenders would report lower motivation for treatment than urban drug offenders, and that this difference would be associated with early dropout from treatment. 
It was also expected that poorer health status would be associated with dropout. Findings may be used to inform correctional administrators and treatment providers working with the criminal justice population of factors related to dropping out of treatment prematurely, and thereby help to direct resources in the most fiscally efficient manner

\section{Residency and Physical Health Status}

Results of the study suggest that an offender's place of residency and physical health status are useful factors to consider during both the treatment screening process and treatment itself. Retention, and conversely dropout, was found to be significantly related to an offender's motivation for treatment. Individuals high in motivation engage more easily in treatment, form better therapeutic relationships, stay longer in treatment, and have better therapeutic outcomes than persons whose motivation is low (Broome, Simpson, \& Joe, 1999). In this study, motivation for treatment was assessed with the TCU Motivation Assessment (Simpson \& Joe, 1993). Partial support was found for the hypothesis that rural offenders would report lower motivation for treatment than urban offenders. Specifically, the analysis of the three subscales of the TCU Motivation Assessment (problem recognition, treatment readiness, desire for help; Simpson \& Joe, 1993 ) indicated that rural drug offenders differed significantly from their urban counterparts only in their desire for help. No significant differences were found with respect to the problem recognition and treatment readiness subscales.

\section{Motivation, Attitude Change and Help Seeking}

According to the stages of change model proposed by Simpson \& Joe (1993), substance abusers progress through a series of motivational stages (problem recognition, desire for help, treatment readiness) that underlie internal motivation for treatment of 
their addictive behavior. The desire for help stage is conceptually similar to individuals in the contemplation stage of the Transtheoretical model developed by Prochaska \& DiClemente (1986). Substance-abusing individuals may recognize a problem and wish to change their behavior, but may not be ready to commit to change or see a need for treatment. Some whose sense of self-efficacy is low may shy away from difficult tasks or be weakly committed to the goals they have set. Self-doubt about their capabilities may decrease their motivation and increase the likelihood of premature dropout (Hiller et al., 1999)

While many drug offenders in treatment understand their drug use has created serious problems in their lives and the lives of their families (perhaps with the help of motivational interviewing techniques; Miller \& Rollnick, 1995), some are resistant to the idea that they need help from others in getting their lives back in order. In that regard, the finding by Warner \& Leukefeld (2001) that rural inmates were less likely to seek help was supported. It appears that rural drug offenders may have particular difficulty in making the transition from recognizing a problem to acknowledging that they cannot overcome it on their own. They may be more at risk for "doing their own time" (not engaging in prison programming) and rejecting outside help. One plausible explanation for this difficulty may be found in cultural attitudes that discourage help-seeking behavior (e.g., suspiciousness and doubt; Sullivan et al., 1993; Wagenfeld et al., 1994) and the importance placed on independence and self-help found in rural communities (Bushy, 1997). Uncertainty about what goes on in treatment (the metaphorical "black box") is universal, but may be more prevalent among rural residents and make them less treatment savvy. 
Some of these attitudes may have been transmitted across multiple generations of families and are, thus, extremely resistant to change. A lack of resources in a rural community may reinforce these attitudes by forcing rural drug abusers to struggle with their addiction alone. The development of pre-treatment strategies to educate substance abusers and their families about what occurs in treatment and to increase their motivation could help open the therapeutic "black box" and de-mystify the treatment process for them.

\section{Characteristics of Rural Offenders}

An interesting finding was that once in treatment rural offenders were three times more likely than urban offenders to drop out of treatment prematurely. Possibly, rural offenders were still struggling against the realization that they needed help for their substance abuse problem. If they had no history of treatment or had a bad prior treatment experience, coming to a residential treatment program for the first time with other druginvolved offenders may have been a culture shock for them and confirmed their preconceived ideas about treatment

Therapists who have never worked with rural substance abusers are frequently unfamiliar with the culture's unique attitudes, beliefs, and values. If they do not have access to clinical supervision or training that addresses the cultural differences of rural drug abusers, they may fail to learn new intervention skills that would be more effective with the rural population and fall into a "one-size-fits-all" approach to treatment. Not only are they unlikely to develop a positive therapeutic alliance with the client, but they may also increase the possibility that the client will drop out of treatment (Miller \& Rollnick, 1991). Therefore, therapists who treat rural drug abusers should receive training 
in the characteristics and special issues of this culture, particularly if they are from urban communities themselves or are practicing in a rural community. Such training would be helpful to increase retention not only in prison-based programs, but would also carry over into a community setting and improve retention in aftercare services.

Offenders' subjective experiences of prior treatment or the in-prison TC were not examined in this study, but could shed some light on how rural offenders arrive at the decision to remain or drop out of residential treatment. A better understanding of the motivational processes of rural offenders may lead to the development of targeted interventions designed to enhance their engagement in treatment, increase retention, and produce better treatment outcomes. For example, Blankenship, Dansereau, \& Simpson (1999) have reported some success increasing the level of early engagement of a group of probationers using a set of cognitive interventions.

A number of mental and physical health problems were reported by participants in this study, regardless of their residency status. There were no significant differences between rural and urban offenders on any of the mental health indices or on lifetime physical health. Rural offenders did, however, report a significantly higher average number of physical health problems in the year prior to incarceration. Health status tends to deteriorate the longer a person uses drugs and may worsen if health care is inaccessible. In a study by Narevic, Garrity, Schoenberg, Hiller, Webster, Leukefeld, \& Tindall (2006), the health care needs of rural prisoners were more likely to have gone unmet. Furthermore, prisoners whose health care needs were unmet rated their health status as worse and reported more incidents of serious illness than prisoners whose health care needs had been met. They also reported more mental health problems and longer, 
more frequent drug use. Since health care services are generally fewer and far between in rural communities, one might conclude that rural offenders are more likely to experience a greater decline in health status prior to incarceration than urban offenders. This study would then seem to highlight the need for correctional administrators and health service providers to be aware of the variety and severity of their inmates' health problems as early as possible during their incarceration.

\section{Limitations}

There are several limitations associated with this study. First, the number of offenders who dropped out of treatment prematurely was quite small and may have significantly drained the statistical power after only a couple of variables. While it is possible that this particular cohort of drug users was better suited (i.e. matched) to the inprison TC simply by chance and had generally higher motivation for treatment, it seems more likely that offenders may have been responding to more selfish motives. Offenders have a much greater chance of parole if they complete the TC program. Additionally, TC programs are typically more desirable places to serve one's time. Because of their segregation from the general inmate population, TC participants are not subjected to the high levels of criminality and antisocial behavior that characterize much of the daily prison environment, and which can undermine the treatment process. Thus, offenders are more likely to stay in treatment. Future studies should use larger samples with more dropouts to increase statistical power. Another way to increase power would be to use a more precise measure of treatment retention, such as length of stay (e.g. number of days), as opposed to whether or not someone completed the program. 
Specific reasons for dropout were not assessed, but typically include failure to comply with program requirements, health problems, use of drugs during treatment, lack of motivation, and voluntary withdrawal. Neither was the timing of an offender's dropout taken into account. Most dropouts occur in the early stages of treatment when the level of therapeutic engagement is comparatively lower. Dropouts occurring in latter stages of treatment may be due to an entirely different set of reasons or processes. For example, individuals can change from point $\mathrm{A}$ to point $\mathrm{B}$ through maturational effects. In other words, the individual ending treatment is not the same person who began it. Qualitative studies that assess why and when a person dropped out of treatment are needed, and may have implications for how treatment is administered, treatment outcomes, and for determining whether to expend additional resources on someone who did not complete treatment the first time they attempted it. As Hiller et al. (1999) have observed, a greater understanding of the dynamic variables that are at work during treatment is needed if outcomes are to improve.

Because of the potential for future drug-related crimes and losses associated with drug use without treatment, there is an unspoken demand held by treatment professionals and administrators within the correctional system for drug-involved offenders to complete treatment once they are accepted into the program. In that case, it would be easier for treatment staff to overlook some behaviors that otherwise would result in an offender's termination from treatment, thus resulting in fewer dropouts. Again, subsequent analyses with larger numbers of treatment dropouts may yield more meaningful data. 
The stepwise logistic regression analysis used to analyze the data has been criticized on the grounds that it may yield the best mathematical solution to the data, but have little "biological" value (Menard, 1995). For this reason, it is used solely as an exploratory procedure and not to test a theory. Since the goal of this study was to discover relationships between variables, and it was unclear a priori what the final model should include, stepwise regression was an appropriate method to use to provide the most parsimonious set of predictors.

The sampling procedure used in this study was purposive in nature. Study participants were selected specifically because they were a) chronic drug abusers and, b) treatment dropout was a major outcome of interest. Thus, they were not a randomly selected sample of the general prison population, meaning that the findings cannot be generalized to other criminal justice populations. Nor is it assumed that the participants in this study are representative of the population of rural drug offenders. This study examined one rural sample from one rural state. Data from additional samples in Kentucky and other rural states should be collected and examined before more definitive conclusions can be drawn.

Data in this study were based on the offenders' self-report, which may be affected by memory accuracy, deception, and social desirability. Although steps were taken to obtain the most accurate information from them, including the use of trained interviewers, a federal certificate of confidentiality by the Department of Health and Human Services, and cross-validation, the findings presented here may still have been affected by inaccurate reporting. Nevertheless, participants willingly shared a great deal of information regarding their health status and substance use. Research has shown that 
valid self-report data can be obtained in settings where conditions favor truthful selfdisclosure (Wish, 1988). High rates of self-reported substance use disorders among inmates have also been found to be consistent with rates obtained in national epidemiological studies (Peters, Greenbaum, Steinberg, Carter, Ortiz, Fry, \& Valle, 2000).

Further, it is possible that inmates had health problems that they were not aware of at the time the data were collected. Were that the case, the physical health differences among rural and urban inmates reported in this study could have been wiped out or more pronounced depending on the number of problems reported and the residency of the inmates reporting them. Future studies should include more objective clinical examinations to obtain as accurate health information as possible.

Finally, the study is clearly not intended to establish causation but to discover relationships between a number of factors that can be used to identify incarcerated drug offenders who are at greater risk for dropping out of residential treatment and, consequently, reduce wasteful treatment expenditures. Each client possesses unique characteristics that were not measured in this study but, nevertheless, may also be related to retention.

\section{Implications and Recommendations}

This and other studies have shown that drug offenders present with a host of comorbid mental and physical health problems. Rural offenders are particularly at risk for not receiving adequate health care services in their communities because they are unavailable or are too difficult to access. Many may also lack sufficient desire for help. Prisons can be a vital source of preventive interventions and health care services they 
might otherwise never receive. As part of a screening at prison intake, the inclusion of an offender's residency can be applied toward the development of a risk profile (Garrity et al. 2002), which can be used to track the health services utilization of rural offenders in prison. It can also be used to alert prison health care providers to potential health problems, which might lead to more rapid response and, consequently, avert more serious conditions that are expensive to treat. As Garrity et al. (2002) have suggested, such profiles would provide hard evidence upon which to base cost projections for health services and provide a rational basis for making budget requests. As a predictor of substance abuse treatment completion, the inclusion of residency in the screening process can be used to direct rural inmates to pre-treatment education and motivational enhancement strategies geared toward increasing their retention in treatment.

But while the demand for services is great among drug offenders, both rural and urban, the resources necessary to meet them are much more limited. Any efforts to track inmate health, promote healthy lifestyles, educate substance abusers (and perhaps their families) about treatment, or increase their motivation for treatment are likely to entail some additional costs. However, as prior studies have shown, prison-based substance abuse treatment can reduce drug-related crime and relapse, improve health, and is costeffective. Randomized and longitudinal studies are necessary to assess the effectiveness of such efforts on offenders' health status and recidivism as they transition into the community and beyond.

As corrections budgets become tighter, correctional administrators will be forced to make difficult choices about which programs and/or inmate needs are budgeted. This will remain a critical policy issue as long as drug offenders are subject to mandatory 
minimum sentences and continue to experience serious health problems. The treatment of those problems during incarceration is a moral and ethical imperative. The current fiscal climate necessitates that correctional drug and health treatment policies establish priorities that balance treatment need with economic efficiency. Correctional drug treatment programs whose clientele consist of rural residents need to be prepared to address the unique characteristics and treatment issues of those persons to reduce treatment dropout and improve treatment outcomes. This study has demonstrated that at least in one rural state an offender's residency is a factor to be considered in the competition for scarce resources, and is one that can be added without cost to any screening or assessment procedures simply by adding a single question.

The findings presented here also have implications for reentry planning. Most prisoners eventually return to the community. Those who are returning to rural areas may find it difficult to return to a community that still adheres to attitudes intolerant of outside help. They must be connected with supportive aftercare services if the best treatment outcomes are to be realized. Studies such as this underscore the importance of early identification of health problems among rural offenders and creating better linkages with community based health services, especially in rural communities. 


\section{REFERENCES}

Adams, J., Bowman, K., Burke, B., Casson, L., Caviness, L., Coffey, L. E., Devore, J., Durham, J., Ellis, C., Hewitt, D., Hinsdale, M., Johnson, I., Myers, S., Penne, M., \& Zolon, H. (2001). 1999 National Household Survey on Drug Abuse Data Collection Final Report. Rockville, MD: Department of Health \& Human Services, Substance Abuse and Mental Health Services Administration.

Agosti, V., Nunes, E., Stewart, J. W., \& Quitkin, F. M. (1991). Patient factors related to early attrition from an outpatient cocaine research clinic: A preliminary report. International Journal of the Addictions, 26, 3227-3334.

American Correctional Association. (1999a). Inmate health: Part 1. Survey summary. Corrections Compendium, 24(10), 8-17.

American Correctional Association. (1999b). Inmate health: Part 2. Survey summary Corrections Compendium, 24(11), 12-20.

Anglin, M. D. (1988). The efficacy of civil commitment in treating narcotic addiction. In C. G. Leukefeld, \& F. Tims (Eds.), Compulsory treatment of drug abuse: Research and clinical Practice (NIDA Research Monograph 86). Washington, DC: U. S. Government Printing Office.

Anglin, M. D., Brecht, M. L., \& Maddahian, E. (1989). Pretreatment characteristics and treatment performance of legally coerced versus voluntary methadone maintenance admissions. Criminology, 27(3), 537-557. 
Anglin, M. D., Farabee, D. \& Prendergast, (1998). The role of coercion in offender drug treatment. A report to the Physician Leadership on National Drug Policy. Washington, DC: Physician Leadership Group.

Anglin, M. D., \& Hser, Y. I. (1990). Treatment of drug abuse. In M. Tonry \& J. Wilson (Eds.), Drugs and crime (pp. 393-460). Chicago: University of Chicago Press.

Anglin, M. D., Longshore, D., Turner, S., McBride, D., Inciardi, J., \& Prendergast, M. (1996). Studies of the functioning and effectiveness of treatment alternatives to street crime (TASC) programs [Final report]. Los Angeles: UCLA Drug Abuse Research Center.

Anglin, M. D., \& Maugh, T. H. (1992). Ensuring success in interventions with drug using offenders. Annals of the American Academy of Political and Social Sciences, 521, $66-90$.

Anno, B. J. (1997). Health behavior in prisons and correctional facilities. In D. S. Gochman (Ed.), Handbook of health behavior research: Vol. 3. Demography, development, and diversity (pp. 289-303). New York: Plenum.

Apsler, R. (1994). Is drug abuse treatment effective? American Enterprise, 5(2), 46-53.

Ashery, R. S. (1985). Issues in the brief treatment of drug abusers. In R. S. Ashery (Ed.), Progress in the development of cost-effective treatment for drug abusers. (NIDA Research Monograph 58. DHHS Publication No. ADM 85-1401, pp. 1-8). Washington, DC: U. S. Government Printing Office.

Austin, J. (2001). Prisoner reentry: Current trends, practices and issues. Crime \& Delinquency, 47(3), 314-334.

Bagarozzi, D. A. (1982). The family therapists' role in treating families in rural 
communities: A general systems approach. Journal of Marital \& Family Therapy, $8(2), 51-58$.

Ball, J. C., Shaffer, J. W., \& Nurco, D. N. (1983). The day-to-day criminality of heroin addicts in Baltimore: A study in the continuity of offense rates. Drug and Alcohol Dependence, 12, 119-142.

Baumer, E. (1994). Poverty, crack, and crime: A cross-city analysis. Journal of Research on Crime and Delinquency, 31(3), 311-327.

Belenko, S. (2002). Drug courts. In C. G. Leukefeld, F. Tims and D. Farabee (Eds.), Treatment of drug offenders: Policies and issues (pp. 301-318). New York: Springer

Belenko, S. (2001). Research on drug courts: A critical review: 2001 update. New York, NY: National Center on Addiction and Substance Abuse at Columbia University. Belenko, S. (1998). Research on drug courts: A critical review. National Drug Court Institute Review, 1, 1-30.

Belenko, S., Foltz, C., Lang, M. A., \& Sung, H-E. (2004a). The impact on recidivism of residential treatment for high risk drug felons: A longitudinal analysis. Journal of Offender Rehabilitation, 40, 105-132.

Belenko, S. \& Peugh, J. (2005). Estimating drug treatment needs among state prison inmates. Drug and Alcohol Dependence, 77, 269-281.

Belenko, S. \& Peugh, J. (1998). Fighting crime by treating substance abuse. Issues in Science and Technology, 15(1), 53-60.

Beltrane, T. F. (1978). Meeting the special needs of Appalachian alcoholics. Hospital Community Psychiatry, 29, 792-794. 
Bendszus, M., Heinz, G., Weijers, G., Weisbach, G., Wanmuth-Metz, M., Bartsch, A. J., Engels, S., Boning, J., \& Solimosi, L. (2001). Sequential MR imaging and proton MR spectroscopy in patients who underwent recent detoxification for chronic alcoholism: Correlation with clinical and neuropsychological data. American Journal of Neuroradiology 22(10), 1926-1932.

Birecree, E. A., Bloom, J. D., Leverette, M. D., \& Williams, M. (1994). Diagnostic efforts regarding women in Oregon's prison system: A preliminary report. International Journal of Offender Therapy and Comparative Criminology, 38 , $217-230$

Blankenship, J., Dansereau, D. F., \& Simpson, D. D. (1999). Cognitive enhancements of readiness for corrections-based treatment for drug abuse. Prison Journal, 79, 431445.

Broome, K. M., Knight, D. K., Knight, K., Hiller, M. L., \& Simpson, D. D. (1997). Peer, family and motivational influences on drug treatment process and recidivism for probationers. Journal of Clinical Psychology, 53, 387-397.

Broome, K. M., Simpson, D. D., \& Joe, G. W. (1999). Patient and program attributes related to treatment process indicators in DATOS. Drug and Alcohol Dependence, 57, 127-135.

Brown, B. S., Voskuhl, T. C., \& Lehman, P. E. (1977). Comparison of drug abuse clients in urban and rural settings. American Journal of Drug and Alcohol Abuse, 44, 445-454.

Bureau of Justice Statistics (2007, December). Prisoners in 2006. (NCJ 219416).

Washington, DC: U. S. Department of Justice. 
Bureau of Justice Statistics. (2006, October). Drug use and dependence, state and federal prisoners, 2004. (NCJ 213530). Washington, DC: U. S. Department of Justice. Bureau of Justice Statistics. (2006, September). Mental health problems of prison and jail inmates. (NCJ 213600). Washington, DC: U. S. Department of Justice. Bureau of Justice Statistics. (2005, October). Prisoners in 2004. (NCJ 10677).

Washington, DC: U. S. Department of Justice.

Bureau of Justice Statistics. (2004, June). State prison expenditures, 2001. NCJ 202949). Washington, DC: U. S. Department of Justice.

Bureau of Justice Statistics. (2002, July). Prisoners in 2001. (NCJ 195189). Washington, DC: U. S. Department of Justice.

Bureau of Justice Statistics. (2001, December). Violence in the workplace, 1993 - 1999. (NCJ 190076). Washington, DC: U. S. Department of Justice. Bureau of Justice Statistics. (2001, August). Prisoners in 2000. (NCJ 188207). Washington, DC: U. S. Department of Justice.

Bureau of Justice Statistics. (1999, January). Substance abuse and treatment, state and federal prisoners, 1997 (NCJ-172871). Washington, DC: U. S. Department of Justice.

Bury, G. F., O'Kelly, \& Pomeroy, L. (1993). The use of primary care services by drug users attending a HIV prevention unit. Irish Medical Journal, 86(2), 53-55.

Bushy, A. (1997). Mental health and substance abuse: Challenges in providing services to rural clients. In Center for Substance Abuse Treatment (ed.), Bringing Excellence to Substance Abuse Services in Rural and Frontier America. Technical Assistance 
Publication Series 20, Rockville, MD: Substance Abuse and Mental Health Services Administration.

Cahalan, D. (1987). Understanding America's drinking problem. San Francisco: JosseyBass.

Camp, C. G., \& Camp, G. M. (1997). The 1997 corrections yearbook. South Salem, NY: Criminal Justice Institute

Carroll, K. M. (1997). Enhancing retention in clinical trials of psychosocial treatments: Practical strategies. In L. Onken, J. Blaine, \& J. Boren (Eds.), Beyond the therapeutic alliance: Keeping the drug-dependent individual in treatment. (NIDA Research Monograph \#165), Washington, DC: U. S. Government Printing Office Cartwright, W. S. (2000). Cost-benefit analysis of drug treatment services: Review of the literature. Journal of Mental Health Policy and Economics, 3, 11-26.

Center on Addiction and Substance Abuse. (2000). No place to hide: Substance abuse in midsize cities and rural America. New York: Columbia University.

Center on Addiction and Substance Abuse. (1998). Behind bars: Substance abuse and America's prisons-Executive Summary. Available from the world wide web, URL

Chaiken, M. R. (1986). Crime rates and substance abuse among types of offenders. In CrimeRates among drug abusing offenders: Final report to the National Institute of Justice (pp. 12-54). New York: Narcotic and Drug Research.

Chaiken, J. M., \& Chaiken, M. R. (1990). Drugs and predatory crime. In M. Tonry \& J. Q. Wilson (Eds.), Drugs and crime (pp. 203-239). Chicago, IL: University of Chicago Press. 
Chitwood, D. D., McBride, D. C., French, M. T., \& Comerford, M. (1999). Health care need and utilization: A preliminary comparison of injection drug users, and other illicit drug users, and nonusers. Substance Use \& Misuse, 34, 727-746.

Chitwood, D. D., McBride, D. C., Metch, L. R., Comerford, M., \& McCoy, C. B. (1998). A comparison of the need for health care and use of health care by injection-drug users, other chronic drug users, and nondrug users. American Behavioral Scientist, 41, 1107-1122.

Collins, J. J., \& Allison, M. (1983). Legal coercion and retention in drug abuse treatment. Hospital and Community Psychiatry, 34, 1145-1149.

Condelli, W. S., \& DeLeon, G. (1993). Fixed and dynamic predictors of client retention in therapeutic communities. Journal of Substance Abuse Treatment, 10, 11-16.

Condelli, W. S., \& Dunteman, G. H. (1993). Issues to consider when predicting retention in therapeutic communities. Journal of Psychoactive Drugs, 25, 239-244.

Conger, R. (1997). The special nature of rural America. In Z. S. E. Robertson, G. Boyd, L. Beatty, \& N. Kozel (Eds.), Rural substance abuse: State of knowledge and issues (NIDA Research Monograph 168, pp. 37-52.) Rockville, MD: U. S. Department of Health and Human Services.

Conoley, J. C., \& Kramer, J. J. (1989). The tenth mental measurements yearbook (pp. 111-113). Lincoln, NE: University of Nebraska Press.

Cook, F. (2002). Treatment Accountability for Safer Communities: Linking the criminal justice and treatment systems. In C. G. Leukefeld, F. Tims and D. Farabee (Eds.), Treatment of drug offenders: Policies and issues (pp. 105-110). New York: Springer. 
Cook, T. D., \& Campbell, D. T. (1979). Quasi-experimentation: Design and analysis issues for field settings. (pp. 50-59). Boston: Houghton Mifflin.

Cotton-Oldenburg, N. U., Martin, S. L., Jordan, B. K., Sadowski, S. L., \& Kupper, L (1997). Preincarceration risky behaviors among women inmates: Opportunities for prevention. Prison Journal, 77, 281-294.

Cullen, F. T., \& Gilbert, K. E. (1982). Reaffirming rehabilitation. Cincinnati, OH: Anderson.

Davis, M. P., Varga, J., Dickerson, K., Walsh, D., LeGrand, S. B., \& Lagman, R. (2003). Normal-release and controlled-release oxycodone: Pharmacokinetics, pharmacodynamics, and controversy. Support Care Cancer, 11, 84-92. Arlington, VA: Drug Enforcement Administration.

DeLeon, G. (2000). The therapeutic community: Theory, model \& method. New York: Springer Publishing Co.

DeLeon, G. (1991). Retention in drug-free therapeutic communities. In R. W. Pickens, C. G. Leukefeld, \& C. R. Schuster (Eds.), Improving drug abuse treatment (NIDA Research Monograph 106, DHHS Publication No. ADM 91-1754). Rockville, MD: National Institute on Drug Abuse.

DeLeon, G. (1988). Legal pressure in therapeutic communities. Journal of Drug Issues, $18,625-640$.

DeLeon, G. (1984). The therapeutic community: Study of effectiveness (NIDA Research Monograph Series, DHHS Publication No. ADM 84-1286). Rockville, MD: National Institute on Drug Abuse. 
DeLeon, G. , \& Jainchill, N. (1986). Circumstances, motivation, readiness, and suitability as correlates of treatment tenure. Journal of Psychoactive Drugs, 18, 203-208.

DiClemente, C. C. (1993). Creating compliance: An interactive process between patients and providers. In M. Mattson, \& N. Krasnegor (Eds.), Behavioral research in clinical trials: Addictive diseases symposium conducted at the National Institutes of Health Reunion Task Force Series, The Science of Compliance. Bethesda, MD.

Drevets, W. C., Gantier, C., Price, J. C., Kupfer, D. J., Kinehan, P. E., Grace, A. A., Price, J. L., \& Mathis, C. A. (2001). Amphetamine-induced dopamine release in human ventral striatum correlates with euphoria. Biological Psychiatry, $49(2), 81-$ 96.

Dubler, N. N. (1998). The collision of confinement and care: End-of-life care in prisons and jails. Medicine \& Ethics, 26, 149-156.

Elliott, D. S., \& Huizinga, D. (1984). The relationship between delinquent behavior and ADM problems. Paper presented at the ADAMHA/OJJDP State-of-the-art Research Conference on Juvenile Offenders with Serious Drug, Alcohol, and Mental Health Problems. Rockville,MD.

Falkin, G. P., Prendergast, M., \& Anglin, M. D., (1994). Drug treatment in the criminal justice system. Federal Probation, 58, 31-36.

Falkin, G. P., Wexler, H. K., \& Lipton, D. S. (1992). Drug treatment in state prisons. In D. R. Gerstein \& H. J. Harwood (Eds.). Treating drug problems (Vol. II, pp. 89132). Washington, DC: National Academy Press. 
Field, G. D. (2002). Historical trends of drug treatment in the criminal justice system. In C. G. Leukefeld, F. Tims, \& D. Farabee (Eds), Treatment of drug offenders: Policies and Issues. New York: Springer.

Field, G. D. (1992). Oregon prison drug treatment programs. In C.G. Leukefeld \& F.M. Tims (Eds.), Drug abuse treatment in prisons and jails. (NIDA Research Monograph 118, DHHS Publication No. ADM 92-1884, pp. 142-155). Rockville, MD: National Institute on Drug Abuse.

Field, G. D. (1989). A study of the effects of intensive treatment on reducing the criminal recidivism of addicted offenders. Federal Probation, 53(10), 51-56.

Fingarette, H. (1988). Heavy drinking: The myth of alcoholism as a disease. Berkeley: University of California Press.

Finney, J. W., \& Moos, R. H. (1986). Matching patients with treatments: Conceptual and methodological issues. Journal of Studies on Alcohol, 47, 122-134.

French, M. T. (1995). Economic evaluation of drug abuse treatment programs:

Methodology and findings. American Journal of Drug and Alcohol Abuse, 2l, $111-125$.

French, M. T., \& Martin, R. F. (1996). The costs of drug abuse consequences: A summary of research findings. Journal of Substance Abuse Treatment, 13, 453466.

French, M. T., McGeary, K. A., Chitwood, D. D., \& McCoy, C. B. (2000). Chronic illicit drug use, health services utilization, and the cost of medical care. Social Science and Medicine, 50, 1703-1713. 
French, M. T., Zarkin, G. A., Hubbard, R. L., \& Rachal, J. V. (1991). The impact of time in treatment on the employment and earnings of drug abusers. American Journal of PublicHealth, 81, 904-907.

Garrity, T. F., Hiller, M. L., Staton, M., Webster, J. M., \& Leukefeld, C. G. (2002).

Factors predicting illness and health services use among male Kentucky prisoners with a history of drug abuse. The Prison Journal, 82, 295-313.

Gastfriend, D. R., \& McClellan, A. T. (1997). Treatment matching: theoretical basis and practical implications. Med. Clin. North America, 81, 945-966.

Gendreau, P. (1996). Offender rehabilitation: What we know and what needs to be done. Criminal Justice and Behavior, 24, 414-431.

Gendreau, P. (1981). Treatment in corrections: Martinson was wrong. Canadian Psychology, 22. Chicago, IL: University of Chicago Press.

Gerstein, D., \& Harwood, H. (Eds.). (1990). Treating drug problems: A study of the evolution, effectiveness, and financing of public and private drug treatment systems: Vol. I. Washington, DC: National Academy Press.

Gerstein, D., Johnson, R. A., Harwood, H. J., Fountain, D., Suter, N., \& Malloy, K. (1994).Evaluating recovery services: The California drug and alcohol treatment assessment (CALDATA). Sacramento: CA. State of California Department of Alcohol and Drug Programs.

Getting a handle on prison overcrowding. (2007, May 23). Press Register.

Gostin, L. (1991). Compulsory treatment for drug-dependent persons: Justifications for a public health approach to drug dependency. The Milbank Quarterly, 69, 561-592.

Government Accountability Office (2000). Federal prisons: Responses to questions 
related to containing health care costs for an increasing inmate population. (NCJ 184108) Rockville, MD: National Institute of Justice.

Griffith, J. D., Hiller, M. L., Knight, K., \& Simpson, D. D. (1999). A cost-effectiveness analysis of in-prison therapeutic community treatment and risk classification. Prison Journal, 79(3), 352-368.

Hammett, T. M., \& Harmon, P. (1999). Sexually transmitted diseases and hepatitis: Burden of disease among inmates. In 1996-1997 Update: HIV/AIDS, STDs, and TB in correctional facilities (National Institute of Justice, NCJ 157642).

Washington, DC: U. S. Department of Justice.

Hammett, T. M., Harmon, P., \& Maruschak, L. (1999). 1996-1997 Update: HIV, AIDS, STDs, and TB in correctional facilities. U. S. Department of Justice, National Institute of Justice, and Centers for Disease Control and Prevention. Washington, DC.

Hammett, T. M., Gaiter, J. L., \& Crawford, C. (1998). Reaching seriously at-risk populations: Health interventions in criminal justice settings. Health Education and Behavior, 25(1), 99-120.

Harm, N. J., Thompson, P. J., \& Chambers, H. (1998). The effectiveness of parent education for substance abusing women offenders. Alcoholism Treatment Quarterly, 16(3), 63-77.

Hartnoll, R. (1992). Research and help-seeking process. British Journal of Addiction, 87, 429-437. 
Harwood H. (2000). Updating estimates of the economic costs of alcohol abuse in the United States: Estimates, update methods and data. Falls Church, VA: Lewin Group.

Harwood, H. J., Hubbard, R. L., Collins, J. J., \& Rachal, J. V. (1988). The costs of crime and the benefits of drug abuse treatment: A cost-benefit analysis using TOPS data. In C. G. Leukefeld \& F. M. Tims (Eds.), Compulsory treatment of drug abuse: Research and clinical practice. (Research Monograph Series 86. DHHS Publication No. ADM 88-1578, pp. 209-235). Rockville, MD: National Institute on Drug Abuse.

Hegamin, A., Longshhore, D., \& Monohan, G. (2002). Health services in correctional settings: Emerging issues and model strategies. In C. G. Leukefeld, F. Tims, \& D. Farabee (Eds.), Treatment of drug offenders: Policies and issues. New York: Springer.

Henderson, D. J. (1998). Drug abuse and incarcerated women. Journal of Substance Abuse Treatment, 15, 579-587.

Herz, D. \& Murray, R. (2003). Exploring arrestee drug use in rural Nebraska. Journal of Drug Issues, 33(1), 99-117.

Hill, S. Y., DeBellis, M. D., Keshaven, M. S., Lowers, L., Shen, S., Hall, J., \& Pitts, T. (2001). Right amygdala volume in adolescent and young adult offspring from families at high risk for developing alcoholism. Biological Psychiatry, 49(11), 1894-1905. 
Hiller, M. L., Knight, K., Broome, K. M., \& Simpson, D. D. (1998). Legal pressure and treatment retention in a sample of long-term residential programs. Criminal Justice and Behavior, 25, 463-481.

Hiller, M. L., Knight, K., Rao, S. R. \& Simpson, D. D. (2002). Assessing and evaluating mandated correctional substance abuse treatment. In C. G. Leukefeld, F. Tims, \& D. Farabee (Eds.), Treatment of drug offenders: Policies and issues. New York: Springer.

Hitchcock, H. C., Stainback, R. D., \& Roque, G. M. (1995). Effects of halfway house placement on retention of patients in substance abuse aftercare. American Journal of Drug and Alcohol Abuse, 21(3), 379-390.

Hodgson, R. (1994). Treatment of alcohol problems. Addiction, 89, 1529-1534.

Hoffmann, N., Halikas, J., Mee-Lee, D., et al. (1991). American Society of Addiction Medicine-patient placement criteria for the treatment of psychoactive substance abuse disorders. American Society of Addiction Medicine. Washington, DC.

Holder, H. D. (1987). Alcoholism treatment and potential health care cost saving. Medical Care, 25(I), 52-71.

Holder, H. D., \& Blose, J. O. (1992). The reduction of health care costs associated with alcoholism treatment: A 14-year longitudinal study. Journal of Studies on Alcohol, 53, 293-302.

Horvath T. A. (2000). Alcoholism: 12-step isn't for everyone. The National Psychologist, 9(4), 1-2. 
Horvath, A. O., \& Symonds, B. D. (1991). Relation between working alliance and outcome in psychotherapy: A meta-analysis. Journal of Counseling Psychology, $38,139-149$.

Hser, Y., Polinsky, M. L., Maglione, M., \& Anglin, D. M. (1999). Matching clients' needs with drug treatment services. Journal of Substance Abuse Treatment, 16(4), 299-305.

Hubbard, R. L., Craddock, S. G., Flynn, P. M., Anderson, J., Etheridge, R. M. (1997). Overview of 1-year follow-up outcomes in the Drug Abuse Treatment Outcome Study (DATOS). Psychology of Addictive Behavior, 11, 261-278.

Hubbard, R. L., Marsden, M. E., Rachal, J. V., Harwood, H. J., Cavanaugh, E. R., \& Ginzburg, H. M. (1989). Drug abuse treatment: A national study of effectiveness. Chapel Hill, NC: University of North Carolina Press.

Inciardi, J. A. (1993). Drug treatment and criminal justice. Newbury Park, CA: Sage. Inciardi, J. A., \& Goode, J. L. (July, 2003). Miracle medicine or problem drug? Oxycontin and prescription drug abuse. Consumers Research, 17-21.

Inciardi, J. A., Martin, S. S., Butzin, C. A., Hooper, R. M., \& Harrison, L. D. (1997, Spring). An effective model of prison-based treatment for drug-involved offenders. Journal of Drug Issues, 27, 261-278.

Inciardi, J. A., \& McBride, D. C. (1991). Treatment alternatives to street crime: History, experiences, and issues. National Institute on Drug Abuse (DHHS Pub. No. ADM 91-1749). Washington, DC: U.S. Government Printing Office.

Institute of Medicine. (1990). Broadening the base of treatment for alcohol problems. Washington, DC: National Academy Press. 
Jacobsen, L. K., Giadd, J. N., Gottschalk, C., Kosten, T. R., \& Krystal, J. H. (2001).

Quantitative morphology of the caudate and putamen in patients with cocaine dependence. American Journal of Psychiatry, 158(3), 486-489.

Jernigan, T. L., Gamst, A. C., Archibald, S. L., Fennema-Notestine, C., Mindt, M. P., Marcotte, T. L., Heaton, R. K., Ellis, R. J., \& Grant, I. (2005). Effects of methamphetamine dependence and HIV infection on cerebral morphology. American Journal of Psychiatry, 162(8), 1461-1472.

Joe, G. W., Simpson, D. D., \& Broome, K. M. (1998). Effects of readiness for drug abuse treatment on client retention and assessment of process. Addiction, 93, 1177-1190.

Jones, K. R., \& Vischi, T. R. (1979). Impact of alcohol, drug use and mental health treatment on medical care utilization. Supplement to Medical Care, 17(12).

Karson, S. \& Gesumaria,R. V. (1997). Program description and outcome of an enhanced, six-month residential therapeutic community. In G. DeLeon (Ed.), Community as method: Therapeutic communities for special populations and special settings (pp. 199-212). Westport, CT: Greenwood Publishing Company.

Keaveny, M. E., \& Zausniewski, J. A. (1999). Life events and psychological well-being in women sentenced to prison. Mental Health Nursing, 20, 73-89.

Kelleher, K. J., Rickert, V. I., Hardin, B. H., Pope, S. K., \& Farmer, F. L. (1992). Rurality and gender: Effects on early adolescent alcohol use. American Journal of Diseases of Children, 146(3), 317-322.

Kendig, N., Stough, T., Austin, P., Kummer, L., Swetz, A.,\& Vlahov, D. (1994). Profile of HIV seropositive inmates diagnosed in Maryland's state correctional system. Public Health Reports, 109(6), 756-760. 
Kim, S. J., Lyoo, K. I., Hwang, J., Chung, A., Sung, Y. H., Kim, J., Kwon, D., Chang, K. H., \& Renshaw, P. F. (2005). Prefrontal gray-matter changes in short-term and long-term abstinent methamphetamine abusers. International Journal of Neuropsychopharmacology, 9(2), 221-228.

Knight, K., Hiller, M. T., Broome, K. M., \& Simpson, D. D. (2000). Legal pressure, treatment readiness, and engagement in long-term residential programs. Journal of Offender Rehabilitation, 31(1/2), 101-115.

Knight, K., Simpson, D. D., \& Hiller, M. L. (1999). Three-year reincarceration outcomes for in-prison therapeutic community treatment in Texas. Prison Journal, 79(3), $337-351$.

Kosten, T. R., Rounsaville, B. J., \& Kleber, H. A. (1983). Concurrent validity of the Addiction Severity Index. Journal of Nervous and Mental Disease, 171, 606-610

Leshner, A. I. (1997). Addiction is a brain disease, and it matters. Science, 278(5335), 45 47.

Leukefeld, C. G. (1985). The clinical connection: Drugs and crime. International Journal of the Addictions, 20, 1049-1064.

Leukefeld, C., \& Haverkos, H. (1992). Sexually transmitted diseases. In T. Gullotta, G. Adams, \& R. Montemayer (Eds.), Adolescent sexuality: Advances in adolescent development, 5, 161-180. Newbury Park, CA: Sage.

Leukefeld, C. G., \& Tims, F. (1992). Drug treatment in prisons and jails (NIDA Research Monograph 118). Washington, DC: U. S. Government Printing Office. Leukefeld, C. G., \& Tims, F. (1988). Compulsory treatment: A review of the findings. In C. G. Leukefeld, \& F. M. Tims (Eds.), Compulsory treatment of drug abuse: 
Research and clinical practice. (NIDA Research Monograph 86. DHHS

Publication No. ADM 88-1578, pp. 236-251). Washington, DC: U. S.

Government Printing Office.

Leukefeld, C. G., Tims, F. M., \& Farabee, D. (Eds.). (2002). Treatment of drug offenders: Policies and issues. New York: Springer.

Liebling, A. (1994). Suicide amongst women prisoners. Howard Journal, 33(1), 1-9.

Lindquist, C. H., \& Lindquist, C. A. (1999). Health behind bars: Utilization and evaluation of medical care among jail inmates. Journal of Community Health, 24(4), 285-303.

Lipton, D. S. (1995, November). The effectiveness of treatment for drug abusers under criminal justice supervision. (National Institute of Justice Research Report, NCJ 157642). Washington, DC: U. S. Department of Justice.

Lipton, D. S., (1994). The correctional opportunity: Pathways to drug treatment for offenders. Journal of Drug Issues, 24, 331-348.

Liu, X., Matochik, J. A., Cadet, J., \& London, E. D. (1998). Smaller volume of prefrontal lobe in polysubstance abusers: A magnetic resonance imaging study. Neuropsychopharmacology, 18(4), 243-252.

Lo, C. C. \& Stephens, R. C. (2002). Arrestees' perceived need for substance-specific treatment: Exploring urban - rural differences. American Journal of Drug and Alcohol Abuse, 28,(4), 623-642.

Logan, T. K., Hoyt, W. H., McCollister, K. E., French, M. T., Leukefeld, C. G., \& Minton, L. (2004). Economic evaluation of drug court: Methodology, results, and policy implications. Evaluation and Program Planning, 27, 381-396. 
MacCoun, R. (1998). Toward a psychology of harm reduction. American Psychologist, 53, 1199-1208.

Marlatt, G. A. (1988). Matching clients to treatment: Treatment models and stages of change. In D. M. Donovan \& G. A. Marlatt (Eds.), Assessment of addictive behaviors (pp. 474-483). New York: Guilford Press.

Marlow, D. B., \& Kirby, K. C. (1999). Effective use of sanctions in drug courts: Lessons from behavioral research. National Drug Court Institute Review, 2(1), 1-32.

Marquart, J. W., Brewer, V. E., \& Mullings, J. L. (1999). Health risk as an emerging field within the new penology. Journal of Criminal Justice, 27, 143-154.

Marquart, J. W., Merianos, D. E., Hebert, J. L., \& Carroll, L. (1997). Health condition and prisoners: A review of research and emerging areas of inquiry. The Prison Journal, 77, 184-208.

Martin, S. L., Cotton, N. U., Browne, D. C., Kurz, B. \& Robertson, E. (1995). Family violence and depressive symptomatology among incarcerated women. Journal of Family Violence, 10, 399-411.

Martin, S. S., Butzin, C. A., \& Inciardi, J. A. (1995). Assessment of a multistage therapeutic community for drug-involved offenders. Journal of Psychoactive Drugs, 27(1), 109-116.

Martin, S. S., Butzin, C. A., Saum, S. A., \& Inciardi, J. A. (1999). Three-year outcomes of therapeutic community treatment for drug-involved offenders in Delaware. Prison Journal, 79, 294-320.

Martinson, R. (1974). What works? Questions and answers about prison reform. The Public Interest, 35, 22-54. 
Maruschak, L. M. (1999). HIV in prisons and jails, 1996. In 1996-1997 Update:

HIV/AIDS, STDs, and TB in correctional facilities (National Institute of Justice, NCJ 157642). Washington, DC: U. S. Department of Justice.

Mateyoke-Scrivner, A., Webster, J. M., Hiller, M. L., Staton, M., \& Leukefeld, C. (2003).

Criminal history, physical and mental health, substance abuse, and services use among incarcerated substance abusers. Journal of Contemporary Criminal Justice, 19(1), 82-97.

Mauser, E., Van Stelle, K. R., \& Moberg, D. P. (1994). The economic impact of diverting substance abusing offenders into treatment. Crime and Delinquency, 40(4), 568588.

McBride, D., \& McCoy, C. B. (1992). The drugs-crime relationship: An analytical framework. The Prison Journal, 73, 257-278.

McClellan, A. T., \& Alterman, A. I. (1991). Patient treatment matching: A conceptual and methodological review with suggestions for future research. In R. W. Pickens, C. G. Leukefeld, \& C. R. Schuster (Eds.), Improving drug abuse treatment (NIDA Research Monograph 106, DHHS Publication No. ADM 911754). Rockville, MD: National Institute on Drug Abuse.

McClellan, A. T., Luborsky, L., O'Brien, C. P., \& Woody, G. E. (1980). An improved diagnostic evaluation instrument for substance abuse patients: The Addiction Severity Index. Journal of Nervous and Mental Disease, 168, 26-33.

McClellan, T., Woody, G., Luborsky, L., O'Brien, C., \& Druley, K. (1983). Increased effectiveness of substance abuse treatment: A prospective study of patienttreatment "matching." Journal of Nervous and Mental Disease, 17I(10), 597-605. 
McClellan, T., Woody, G., Luborsky, L., O'Brien, C., \& Druley, K. (1982). Is treatment for substance abuse effective? Journal of the American Medical Association, 247 (10), 1423-1428.

McCollister, K. E., French, M. T., Inciardi, J. A., Butzin, C. A., Martin, S. S., \& Hooper, R. M. (2003b). Post-release substance abuse treatment for criminal offenders: A cost-effectiveness analysis. Journal of Quantitative Criminology, 19, 389-407.

McCollister, K. E., French, M.T., Prendergast, M. Hall, E., \& Sacks, S. (2004). Longterm cost-effectiveness of addiction treatment for criminal offenders. Justice Quarterly, 21, 659-679.

McCollister, K. E., French, M. T., Prendergast, M., Wexler, H., Sacks, S., \& Hall, E. (2003a). Is in-prison treatment enough? A cost-effectiveness analysis of prisonbased treatment and aftercare services for substance-abusing offenders. Law and Policy, 25, 63-82.

McCorkel, J. A., Butzin, C. A., Martin, S. S., \& Inciardi, J. A. (1998). Use of health care services in a sample of drug-involved offenders: A comparison with national norms. American Behavioral Scientist, 41, 1079-1111.

McDonald, D. C. (1995). Managing prison health care and costs. Washington, DC: National Institute of Justice. McDonald, D. C. (1999). Medical care in prison. In M. Tonry \& J. Petersilia (Eds.), Prisons, (pp. 427-478). Chicago: University of Chicago Press

Medard, S. (1995). Applied logistic regression analysis. Quantitative Applications in the Social Sciences. Sage Publication Series, 106, Thousand Oaks, CA: Sage. 
Milam, J. R., \& Ketcham, K. (1981). Under the influence: A guide to the myths and realities of alcoholism. Seattle, WA: Madrona Publications.

Miller, W. R., \& Rollnick, S. (1991). Motivational interviewing: Preparing people to change addictive behaviors. New York: Guilford Press.

Mumola, C. J. (1999, January). Substance abuse and treatment, state and federal prisoners, 1997. Bureau of Justice Statistics Special Report (NCJ172871).

Washington, DC: U.S. Department of Justice, Office of Justice Programs.

National Institute of Corrections (1998). Hospice and palliative care in prisons: Special issues in corrections. Longmont, CO: U. S. Department of Justice.

National Institute on Drug Abuse. (July, 2006). Principles of drug abuse treatment for criminal justice populations: A research-based guide. (NIH Publication No. 065316).

National Institute on Drug Abuse. (July, 2006). NIDA announces recommendations to treat drug abusers, save money, and reduce crime. Press release July 24, 2006;

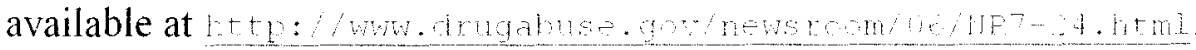

National Institute of Corrections (1991). Intervening with substance-abusing offenders: A framework for action. The report of the National Task Force on Correctional Substance Abuse Strategies. Washington, DC: U. S. Department of Justice. National Institute of Justice (2003). 2000 Arrestee Drug Abuse Monitoring: Annual Report (NCJ 193013). Washington, DC: U. S. Department of Justice. Office of National Drug Control Policy (2000, March). Drug-related crime: ONDCP drug policy information Fact Sheet. (NCJ 181056). Washington, DC: The White House. 
Palmer, T. (1983). The effectiveness issue today: An overview. Federal Probation, 46, 3 10

Palmer, T. (1975). Martinson revisited. Journal of Research in Crime and Delinquency, $12,133-152$.

Peele, S. (1985). The meaning of addiction. Lexington, MA: Lexington Books. Peters, R. H. (1993). Drug treatment in jails and detention settings. In J. A. Inciardi (Ed.), Drug treatment and criminal justice. Newbury Park, CA: Sage.

Peters, R. H., Greenbaum, P. E., Edens, J. F., Carter, C. R., \& Ortiz, M. M. (1998). Prevalence of DSM-IV substance abuse and dependence disorders among prison inmates. American Journal of Drug and Alcohol Abuse, 24, 573-587.

Petersilia, J. (2001). Prisoner reentry: Public safety and reintegration challenges. The Prison Journal, 8I(3), 360-375.

Pfefferbaum, A., Sullivan, E. V., Mathalon, D. H., Shear, P. K., Rosenbloom, M. J., \& Lim. K. O. (1995). Longitudinal changes in magnetic resonance imaging brain volumes in abstinent and relapsed alcoholics. Alcoholism: Clinical and Experimental Research. 19(5), 1177-1191.

Platt, J. J., Burhringer, G., Kaplan, C. D., Brown, B. S., \& Taube, D. O. (1988). The prospects and limitations of compulsory treatment for drug addiction. Journal of Drug Issues, 18, 495-525.

Pompi, K. F., \& Resnick, J. (1987). Retention of court-referred adolescents and young adults in the therapeutic community. American Journal of Drug and Alcohol Abuse, 13, 309-325. 
Prendergast, M. L., \& Podus, D. (2000). Drug treatment effectiveness: An examination of conceptual and policy issues. Substance Use \& Misuse, 35, 1629-1657.

Ravndal, E., \& Vaglum, P. (1991). Psychopathology and substance abuse as predictors of program completion in therapeutic communities for drug abusers: A prospective study. Acta Psychiatrica Scandinavica, 83, 217-222.

Rhoades, J. A., \& Chu, M. C. (2000). Health insurance status of the civilian noninstitutionalized population: 1999. Rockville, MD: Agency for Healthcare Research and Quality.

Rice, D. P., Kelman, S., Miller, L. S., \& Dunmeyer, S. (1990). The economic costs of alcohol and drug abuse and mental illness: 1985. Rockville, MD: National Institute on Drug Abuse.

Ross, P. H., \& Lawrence, J. E. (1998). Health care for women offenders. Corrections Today, 60(7), 122-127.

Safran, J. D., \& Muran, J. C. (Eds.) (1995). The therapeutic alliance [Special issue]. In Session. Psychotherapy in Practice, I.

Salmon, R. W. \& Salmon, R. J. (1983). The role of coercion in rehabilitation of drug abusers. International Journal of the Addictions, 18, 9-21.

Samenow, S. E. (1984). Inside the Criminal Mind. New York: Crown Business.

Selwyn, P. A., Budner, N. S., Weissman, M. M., Kleber, H. D., \& Wilber, C. H. (1994). The heterogeneity of psychiatric diagnosis in treated opiate addicts. Archives of General Psychiatry, 39, 161-166.

Simpson, D. D., \& Joe, G. W. (1993). Motivation as a predictor of early dropout from drug abuse treatment. Psychotherapy, 30, 357-368. 
Simpson, D. D., Joe, G. W., Fletcher, B. W., Hubbard, R. L., \& Anglin, M. D. (1999). A national evaluation of treatment outcomes for cocaine dependence. Archives of General Psychiatry, 56, 507-514.

Simpson, D. D., Joe, G. W., \& Rowan-Szal, G. A. (1997). Drug abuse treatment retention and process effects on follow-up outcomes. Drug and Alcohol Dependence, 47, 227-235.

Sindelar, J. L., Jofre-Binet, M., French, M. T., \& McClellan, A. T. (2004). Costeffectiveness analysis of addiction treatment: Paradoxes of multiple outcomes. Drug and Alcohol Dependence, 73, 41-50.

Single, E. (1995). Defining harm reduction. Drug and Alcohol Review, 14, 287-290.

Singer, M. I., Bussey, J., Song, L. Y., \& Lunghofer, L. (1995). The psychosocial issues of women serving time in jail. Social Work, 40, 103-113.

Sirotnik, K. A., \& Roffe, M. W. (1977). An investigation of the feasibility of predicting outcome indices in the treatment of heroin addiction. International Journal of the Addictions, 12, 755-775.

Stashenko, J. (1999). State outlines timetable for ban on smoking in prisons. Associated Press, July 21, 1999.

Steiner, C. (1971). Games alcoholics play. New York: Grove Press.

Sullivan, W. P. Hasler, M. D., \& Otis, A. G. (1993). Rural mental health practice: Voices from the field, families in society. Journal of Contemporary Human Services, 74, 493-502.

Taxman, F. S. (1998a). Reducing recidivism through a seamless system of care: Components of effective treatment, supervision, and transition services in the 
community. (Prepared for Office of National Drug Control Policy Treatment and

Criminal Justice System Conference). Greenbelt, MD: University of Maryland, College Park.

Taxman, F. S., \& Messina, N. P. (2002). Civil commitment: A coerced treatment model.

In C. G. Leukefeld, F. Tims, \& D. Farabee (Eds.), Treatment of drug offenders: Policies and issues. New York: Springer.

Thompson, P. M., Hayashi, K. M., Simon, S. L., Geaga, J. A., Hong, M. S., Sui, Y., Lee, J. Y., Toga, A. W., Ling, W., \& London, E. D. (2004). Structural abnormalities in the brains of human subjects who use methamphetamine. Journal of Neuroscience, 24(26), 6028-6036.

Thorburn, K. M. (1995). Health care in correctional facilities. Western Journal of Medicine, 163, 560-564.

Van Voorhis, P. (1987). Correctional effectiveness: The high cost of ignoring success. Federal Probation, 51, 56-62.

Vigdal, G. L., \& Stadler, D. W. (1992). Comprehensive system development in corrections for drug -abusing offenders: The Wisconsin Department of Corrections. Drug abuse treatment in prisons and jails. (Research Monograph 118). Rockville, MD: National Institute on Drug Abuse.

Vlahov, D. T., Brewer, F., Castro, K. G., Narkunas, J. P., Salive, M. E., Ullrich, J., \& Munoz, A. (1991). Prevalence of antibody to HIV-1 among entrants of US correctional facilities. Journal of the American Medical Association, 265, 11291132. 
Volkow, N. D., Chang, L., Wang, G., Fowler, J. S., Leonito-Yee, M., Fransechi, D., et al. (2001b). Association of dopamine transporter reduction with psychomotor impairment in methamphetamine abusers. American Journal of Psychiatry, 158(3), 377-382.

Volkow, N. D., Wang, G., Fowler, J. S., Logan, J., Gatley, S. J., Wong, C., Hitzemann, R., \& Pappas, N. R. (1999). Reinforcing effects of psychostimulants in humans are associated with increases in brain dopamine and occupancy of $D(2)$ receptors. Journal of Psychopharmacology and Experimental Therapeutics, 291(1), 409415.

Volkow, N. D., Wang, G., Fowler, J. S., Logan, J., Hitzemann, R. J., Ding, Y. S., et al. (1996). Decreases in dopamine receptors but not in dopamine transporters in alcoholics. Alcoholism: Clinical and Experimental Research, 20(9), 1594-1598.

Volkow, N. D., Fowler, J. S., Wang, G., Hitzemann, R. J., Logan, J., Schlyer, D. et al. (1993). Decreased dopamine $D(2)$ receptor availability is associated with reduced frontal metabolism in cocaine abusers. Synapse, 14(2), 169-177.

Wagenfeld, M. O., Murray, J. D., Mohatt, D. F., \& DeBruyn, J. C. (1994). Mental health and rural America: 1980-1993. An Overview and Annotated Bibliography. (NIH Publication No: 94-3500). Rockville, MD: Health Resources and Services Administration and National Institute of Mental Health.

Walker, R., Logan, T. K., Bradshaw, G., Leukefeld, C. G., Goltz, M., \& Stevenson, E. (2003). Kentucky Substance Abuse Treatment Outcome Study (KTOS): FY 2002 follow-up findings. (Tech. Rep. No. 2004-03). University of Kentucky, Center on Drug and Alcohol Research. 
Wang, G. J., Volkow, N. D., Fowler, J. S., Logan, J., Hitzemann, R. J., Pappas, N. S., et al. (1997). Dopamine D(2) receptor availability in opiate-dependent subjects before and after naloxone precipitated withdrawal. Neuropsychopharmacology, $16(2), 174-182$.

Warner, B. D., \& Leukefeld, C. G. (2001). Rural-urban differences in substance use and treatment utilization among prisoners. American Journal of Drug and Alcohol Abuse, 27(2), 265-280.

Wexler, H. K., Melnick, G., Lowe, L., \& Peters, J. (1999). Three-year reincarceration outcomes for Amity in-prison therapeutic community and aftercare in California. Prison Journal, 79(3), 320-336.

Wish, E. D. (1988). Identifying drug-abusing criminals. In C. G. Leukefeld \& F. M. Tims (Eds.), Compulsory treatment of drug abuse: Research and clinical practice (NIDA Research Monograph 86, DHHS Publication No. ADM 94-3713). Washington, DC: U. S. Government Printing Office.

Wish, E. D., \& O'Neil, J. A. (1989). Drug use forecasting (DUF). National Institute of Justice Research Report. Washington, DC: U.S. Department of Justice.

Yochelson, S. \& Samenow, S. E. (1984). The criminal personality. New York: Aronson. Young, D. \& Belenko. S. (2002). Program retention and perceived coercion in three models of mandatory drug treatment. Journal of Drug Issues, 32, 297-328.

Zarkin, G. A., French, M. T., Anderson, D. W., \& Bradley, C. J. (1994). A conceptual framework for the economic evaluation of substance abuse interventions. Evaluation and Program Planning, 17, 409-418. 
Zlotnick, C. (1997). Posttraumatic stress disorder (PTSD), PTSD comorbidity, and childhood abuse among incarcerated women. Journal of Nervous and Mental Health Disease, 185, 761-763. 


\section{CURRICULUM VITAE}

\section{Christopher G. Block \\ Department of Educational \& Counseling Psychology \\ University of Louisville \\ Louisville, Kentucky 40292}

Address: Home - 3117 Wynbrooke Circle

Louisville, Kentucky 40241

502.326 .3795

502.836 .0613 (cell)
Work - Division of Mental Health 3001 West Highway 146 LaGrange, Kentucky 40032 502.222.9441, ext. 4199

\section{EDUCATION}

May 1991

M.A.

Spalding University

Major: Clinical Psychology

December, 1983

B.A.

University of Louisville

Major: Psychology

\section{LICENSURE/PROFESSIONAL AFFILIATION}

Kentucky State Board of Psychology, Licensed Psychological Associate \#213

\section{HONORS}

2004 Commissioner's Outstanding Employee Award

2004 Governor's Statewide Drug Control Assessment Summit Committee Member 2003 Multi-agency Drug Abuse Work Group Co-Chair 2001 Department of Corrections Continuing Excellence Award 1998 Drug \& Alcohol Treatment Summit: Strategies for a Safe City, City of Louisville 1996 Department of Corrections Continuing Excellence Award

\section{CURRENT PROFESSIONAL EXPERIENCE}

January 2005 - Present

Licensed Psychological Associate, Sex Offender Risk Assessment Unit, Kentucky Justice Cabinet, Department of Corrections, LaGrange, Kentucky

Perform Comprehensive Sex Offender Presentence Evaluations on adult convicted sexual offenders, as 
CURRICULUM VITAE

Christopher G. Block

Page -2-

mandated by Kentucky statute (KRS 532).

\section{PREVIOUS PROFESSIONAL EXPERIENCE}

November, 1999 -

December 2004

December, 1994 -

November 1999

June, 1993 -

September, 1994
Corrections Program Administrator, Kentucky

Justice Cabinet, Department of Corrections, Division of Mental Health, Office of Alcohol \& Other Drug Abuse Programs, LaGrange, Kentucky

Responsible for the daily operation of statewide residential and community-based substance abuse treatment programs for the Department of Corrections. Charged with program development, evaluation, implementation, supervision, and drug policy implementation.

Certified Psychological Associate/Clinical Director, Kentucky Justice Cabinet, Division of Mental Health, Substance Abuse Treatment Program, LaGrange, Kentucky.

Responsibilities: Administer, direct, and provide full range supervisory and psychological duties to a residential substance abuse treatment program for incarcerated male felony offenders. Serve as interdisciplinary team leader, participate and chair ongoing team staffings to assess patient progress and modify individual treatment plans as necessary. Provide individual and group psychotherapy on a regular basis. Perform psychological testing for diagnosis, treatment planning, and parole purposes. Supervise, direct, and assign the work of staff relative to the counseling and treatment of clients. Provide training and direction to staff relative to the performance of their duties, as well as assisting in the development of policies and regulations of the branch. Forty hours per week.

Certified Psychological Associate, Kentucky Justice Cabinet, Division of Mental Health, Assessment \& Classification Center, LaGrange, Kentucky 
April, 1991 -

April, 1992

October, 1990 -

November, 1994

July, 1988 -

July, 1990
Responsibilities included: psychological screening and assessment to facilitate the classification of incarcerated male offenders; crisis intervention; referrals to psychiatric services, as needed. Ten hours per week.

Family Specialist, Center for Behavioral Health, Baptist Hospital East, Louisville, Kentucky

Responsibilities included: individual, marital, and family therapy. Five hours per week.

Offender Rehabilitation Specialist, Kentucky Justice Cabinet, Division of Mental Health, Sex Offender Treatment Program, LaGrange, Kentucky.

Responsibilities included: provided individual and group therapy services to male offenders in a specialized sex offender treatment program; served as a member of a multidisciplinary treatment team; managed an assigned caseload; maintained treatment files; prepared comprehensive parole evaluations. Forty hours per week.

Psychiatric Technician/Case Manager, Ten Broeck Hospital, Louisville, Kentucky.

Responsibilities included: line level implementation of therapeutic programming and some group psychotherapy experience with adolescents; served as a liaison with the family unit, treatment staff, and admitting psychiatrist. Forty hours per week.

\section{PRESENTATIONS}

Purvis, R., Coleman, D., Meyer, T. \& Block, C. "Mental Health and Substance Abuse Issues with Criminal Justice Clients." Kentucky Jailers Association Annual Conference, Owensboro, Kentucky, June, 2002.

Noble, M. \& Block, C. "Alternatives to Incarceration." Presentation at the Judicial College, Lexington, Kentucky, April, 2000. 


\section{CURRICULUM VITAE}

Christopher G. Block

Page -4-

Minton, L., Block, C., \& Abramson, J. "Agency Collaboration of Services for the Addicted Defendant." Kentucky School of Alcohol and other Drug Studies, Northern Kentucky University, July, 2000.

Block, C., Jacobs-Ahjuder, K., \& Kerley, W. "Jail-based drug and alcohol treatment." Kentucky Jailers Association Annual Conference, Owensboro, Kentucky, June 1998.

Purvis, R. \& Block, C. "Typologies and Characteristics of Sex Offenders." Assessment and Treatment of Sexual Offenders: Introductory and Advanced Strategies for Mental Health Professionals, Rough River, Kentucky, February, 1993.

Purvis, R. \& Block, C. Differences in treating sex offenders and other clients. Assessment and Treatment of Sexual Offenders: Introductory and Advanced Strategies for Mental Health Professionals, Rough River, Kentucky, February, 1993.

Block, C. G. "Psychological Aspects of Shoplifting." Presentation in collaboration with the Better Business Bureau Stop Shoplifting Program, Louisville, Kentucky, Ongoing monthly.

Numerous ongoing training presentations to correctional staff. 